\title{
GIAO TIẾP CỦA BÁC SĨ VÀ BỆNH NHÂN \\ TẠI PHÒNG KHÁM TƯ VẤN - MộT NGHIÊN CÚU \\ TRƯỜnG HỢP TẠI AUSTRALIA
}

\author{
Nguyễn Thanh Nga* \\ Học viện Quân y, 160 Phùng Hung, Phúc La, Hà Đông, Hà Nội, Việt Nam
}

Nhận bài ngày 01 tháng 11 năm 2017

Chỉnh sửa ngày 22 tháng 01 năm 2018; Chấp nhận đăng ngày 25 tháng 01 năm 2018

Tóm tắt: Bài báo này phân tích chi tiết một đoạn thoại khám tư vấn giữa một bác sĩ đa khoa và bệnh nhân tại một phòng khám tại một vùng ngoại ô thủ đô Canberra. Nghiên cứu này sẽ chứng minh dấu hiệu của sự dịch chuyển ngôn ngữ khám tư vấn của bác sĩ theo mô hình khám tư vấn lấy người bệnh làm trung tâm được khuyến khích nhân rộng ở Australia. Mục đích của nghiên cứu không chỉ dừng lại ở việc khuyến khích phương thức khám tư vấn lấy người bệnh làm trung tâm mà còn khẳng định sự cần thiết trong việc thay đổi diễn ngôn và lý do dẫn tới sự thay đổi phương thức diễn ngôn của bác sĩ tại thời điểm khám tư vấn cho người bệnh. Số liệu của bài báo được thu thập từ việc ghi âm và ghi chép lại một đoạn thoại giữa bác sĩ và người bệnh. Người nghiên cứu trong bài báo này đã không thực hiện bất cứ hành vi can thiệp nào khi đoạn tư vấn xảy ra, chính vì vậy, thông tin thu được từ cuộc tư vấn là hoàn toàn tự nhiên. Khung lý thuyết nghiên cứu này chấp nhận sử dụng là Phân tích hội thoại (CA) và Ngôn ngữ học chức năng hệ thống (SFL). Kết quả nghiên cứu cho thấy ngôn ngữ của bác sĩ cũng vận hành, không thể ‘đứng yên' khi những dòng ngôn ngữ của xã hội mà nó tồn tại song song đang thay đổi (Helman, 1990: 64). Nói cách khác, dòng ngôn ngữ luôn hướng tới sự gần gũi (informality), tính lịch sự (politeness) và dân chủ (democracy) của Australia (Jones, 2004: 6) đã kéo theo sự dịch chuyển trong ngôn ngữ của bác sĩ.

Tù khóa: khám tư vấn, giao tiếp bác sĩ-bệnh nhân, phân tích hội thoại (CA), ngôn ngữ học chức năng hệ thống (SFL)

\section{Dẫn nhập}

Trong nhiều năm gần đây, việc nghiên cứu ngôn ngữ của bác sĩ khi khám tư vấn với người bệnh, nhìn từ góc độ ngôn ngữ học xã hội, đã trở thành một vấn đề rất đáng quan tâm. Rất nhiều nhà ngôn ngữ, nhà xã hội học đã đóng góp các công trình nghiên cứu và đưa ra những quan điểm trái chiều về vấn đề này (Heath 1982, 1992; Heritage \& Lindström, 1996; Heritage \& Stivers, 1999; Heritage \& Maynard, 2006). Theo Hyden \& Mishler (1999), trái ngược với mô hình 'bác sĩ nói cùng bệnh nhân' (doctor talk with patient - DTWP), lấy người bệnh làm trung tâm (patient-centredness), ngôn ngữ của bác sĩ trong tư vấn khám bệnh truyền thống được mặc định theo một mô hình 'bác sĩ nói với

\footnotetext{
* ĐT.: 84-982204246

Email: nganguyen102005@yahoo.com
}

bệnh nhân' (doctor talk to patient - DTTP), lấy bác sĩ làm trung tâm (doctor-centredness). Mô hình tư vấn này coi người bệnh là đối tượng bị động tiếp nhận lời khuyên của bác sĩ (Frankel, 1990; Fairclough \& Wodak, 1997). Tuy nhiên, hình thức khám tư vấn này đã được khuyến khích thay đổi khi ngôn ngữ của bác sĩ có $\mathrm{xu}$ hướng dịch chuyển sang mô hình DTWP. Chính vì việc lấy người bệnh làm trung tâm được khuyến khích rộng rãi trong các hoạt động của ngành $\mathrm{y}$, việc thể hiện quyền lực của bác sĩ trước người bệnh hoàn toàn không được khích lệ (Fairclough, 2001; Monagle \& Thomas, 1994; Brody, 1997; Hyden \& Mishler, 1999; Steven et al 1999; Pappas \& Perlman, 2002; Bruce, 2009). Bài báo này khảo sát lời thoại của một nam bác sĩ đa khoa tại với một nam bệnh nhân tại một phòng khám ở ngoại ô Canberra, Australia. Mục đích 
của bài báo là dựa vào việc kiểm soát lượt lời và các đặc tính ngữ pháp là thức (mood) và tình thái (modality) trong lời thoại của bác sĩ để giải thích sự chuyển đổi phương thức diễn ngôn theo mô hình DTWP và yếu tố xã hội đã tác động vào sự dịch chuyển này.

Khung lý thuyết mà nghiên cứu này chấp nhận sử dụng là Phân tích hội thoại - Conversation Analysis (CA) của Sacks, Schegloff \& Jefferson (1974) và Ngôn ngữ học chức năng hệ thống - Systemic Functional Linguistics (SFL) - một mô hình nổi tiếng trên thế giới dùng để mô tả các nghiên cứu về ngôn ngữ (xem Halliday, 1985/1994; Halliday \& Matthiessen, 2004). Trong khuôn khổ của đề tài, khung lý thuyết về kiểm soát lượt lời (turn-taking) trong $\mathrm{CA}$ sẽ được khai thác. Đường hướng phân tích căn cứ vào lượt lời và các cấu trúc trong các lượt lời của bác sĩ khi giao tiếp với người bệnh. Đồng thời, nghiên cứu khai thác các đặc tính từ vựng ngữ pháp, cụ thể giới hạn ở thức và tình thái trong diễn ngôn của bác sĩ và người bênh, từ đó tìm hiểu các đặc tính ngữ vực kiến tạo nên sự thay đổi trong ngôn từ của bác sĩ khi tuân theo mô hình DTWP, mô hình lấy người bệnh làm trung tâm.

Nghiên cứu này được chia làm bốn phần chính. Phần 1: Dẫn nhập, Phần 2 giới thiệu khái quát mô hình kiểm soát lượt lời trong $\mathrm{CA}$ và mô hình $\mathrm{SFL}$, đặc biệt chú trọng đến hai khái niệm phân tích chủ chốt ở cấp độ từ vựng và ngữ pháp mà nghiên cứu này thực hiện, đó là thức và tính thái. Phần 3 liên hệ các nghiên cứu có liên quan đến bài viết. Phần 4 đưa ra phương pháp nghiên cứu, tập trung giải thích quá trình lấy số liệu và phân tích số liệu. Phần 5 công bố kết quả tìm được và thảo luận trên kết quả phân tích. Phần 6 kết luận các đặc điểm kiểm soát lượt lời và đặc tính ngữ pháp nổi bật kiến tạo nên đặc trưng diễn ngôn trong lời thoại của bác sĩ trong phương thức DTWP, từ đó giải thích yếu tố xã hội nào đã tác động nên sự thay đổi về mặt hình thức của sự dịch chuyển diễn ngôn của bác sĩ khi tư vấn cho người bệnh theo mô hình DTWP được nhân rộng ở Australia.

\section{Cơ sở lý thuyết}

\subsection{Phân tích hội thoại}

Đề tài này không thể áp dụng toàn bộ hệ thống nghiên cứu của Phân tích hội thoại Conversation Analysis (CA). Vì vậy, khung lý thuyết về kiểm soát lượt lời (turn-taking) trong CA (xem Sacks, Schegloff và Jefferson, 1974) được chấp nhận khai thác. Nghiên cứu chủ yếu dựa vào sự phân tích lượt lời (turn design) và các cấu trúc trong các lượt lời (turn allocation) của bác sĩ khi giao tiếp với người bệnh. Trong thực tế, Sacks, Schegloff \& Jefferson (Ibid.) đã đưa ra một công trình nghiên cứu về hai mô hình được gọi là 'đơn vị cấu thành lượt lời'-'turn-constructional component' (TCC) và 'đơn vị phân bố lượt lời' 'turn-allocational component' (TAC). Trong khi TCC chỉ ra các đơn vị cấu thành lượt lời như từ, cụm từ, mệnh đề hay câu, TAC phản ánh cấu trúc của lượt lời của các bên tham gia hội thoại.

Nếu đưa cả hai mô hình TCC và TAC vào sử dụng trong nghiên cứu này đều có thể cho thấy các đơn vị cấu thành ngôn từ của bác sĩ trong khi giao tiếp với người bệnh. Ví dụ, dựa vào mô hình $\mathrm{TCC}$ nghiên cứu viên có thể hiểu được các đơn vị từ vựng bác sĩ sử dụng khi giao tiếp với bệnh nhân trong tư vấn thăm khám, đánh giá được mức độ kiểm soát lượt lời của bác sĩ với bệnh nhân. Bên cạnh đó, mô hình TAC cho phép nghiên cứu viên quyết định được trong cuộc đàm thoại giữa bác sĩ và người bệnh, ai là đối tượng luôn chủ động kiểm soát lượt lời, thể hiện bằng cách nào. Tuy nhiên, các công trình nghiên cứu của SFL đã chỉ ra rằng các đơn vị từ vựng và ngữ pháp có chức năng thâm nhập rất sâu vào các lớp từ/cụm từ trong hệ thống ngữ vực của ngôn bản (xem Halliday, 1978; Halliday \& Matthiessen, 2004; Martin, 1992; Hoàng Văn Vân, 2005, 2012). Chính vì vậy, mặc dù cả 
hai mô hình $\mathrm{TCC}$ và $\mathrm{TAC}$ của $\mathrm{CA}$ đều có thể phục vụ được mục đích nghiên cứu là chỉ ra mô hình đàm thoại phổ biến của bác sĩ trong hình thức DTWP, tuy nhiên nghiên cứu này chỉ dùng TAC để đo tần số của kiểm soát lượt lời trên ba bình diện: cặp thoại (pairs), chêm xen (inserts) và chỉnh sửa (repairs) cũng như ngôn từ của bác sĩ khi giao tiếp với bệnh nhân và chấp nhận khung lý thuyết SFL để đo đơn vị từ vựng ngữ pháp trong lời thoại của bác sĩ tại cuộc khám tư vấn.

2.2. Ngôn ngũ học chức năng hệ thống - các khái niệm có liên quan đến nghiên cưu

\subsubsection{Cấp độ (stratification)}

Theo Halliday (1978, 1985, 1994), Hasan (1993, 1995, 1999), ngôn ngữ là một quá trình xã hội rất phức tạp trong đó các yếu tố xã hội (the social) và các kí hiệu của ngôn ngữ (the semiotic linguistics) luôn có một sự gắn bó chặt chẽ không thể tách rời. Từ đó, Ngôn ngữ học chức năng hệ thống luôn xem xã hội như là một bộ phận cấu thành của một mô hình lí thuyết gồm bốn cấp độ: ngôn cảnh (context), ngữ nghĩa (semantics), ngữ pháp-từ vựng (lexicogrammar), và âm vị học (phonology). Mối liên hệ giữa các cấp độ này tồn tại hai khái niệm điển hình là 'hiện thực hóa' (realisation). Điều đó có nghĩa là cấp độ dưới trực tiếp hiện thực hóa các ý nghĩa của cấp độ trên trực tiếp nó. Vì nghiên cứu này chỉ tập trung tìm hiểu tần số kiểm soát lượt lời và nguồn tài nguyên từ vựng và ngữ pháp trong lời thoại của bác sĩ với người bệnh để từ đó đưa ra những kết luận về ngữ nghĩa, cấp độ âm vị học sẽ không được đề cập tới trong nghiên cứu này. Từ lý do trên, các cấp độ mô hình SFL được trình bày vắn tắt như sau.

Ở cấp độ ngôn cảnh hay còn gọi là phạm trù tình huống xã hội (categories of social situation), SFL đưa ra một nguyên lý rằng ngôn ngữ bao gồm ba khía cạnh của tình huống lời nói được gọi tên là: trường của ngôn bản (field of discourse), không khí của ngôn bản (tenor of discourse) và phương thức của ngôn bản (mode of discourse) (Halliday \& Hasan, 1989; Hasan, 1999). Trường của ngôn bản đề cập tới những tình huống tự nhiên của các hoạt động xã hội (the nature of the social activity), giải thích những gì đang diễn ra thông qua ngôn ngữ, giải thích các hoạt động hay quá trình hoạt động tại thời điểm diễn ra lời nói. Không khí của ngôn bản đề cập tới bản chất tự nhiên của các mối quan hệ xã hội (the nature of social relations), giải thích sự phân vai trong đoạn thoại, đặc biệt biểu thị đặc tính tự nhiên của vai diễn, ví dụ như mối quan hệ giữa người nói và nguời nghe và mục đích của người tham gia tình huống nói nhằm đạt được một kiểu quan hệ nào đó. Phương thức của ngôn bản đưa ra tín hiệu nhận biết tính tự nhiên của các kênh giao tiếp, đề cập tới vai trò của chính ngôn ngữ trong việc đưa ra các tình huống ngữ cảnh cụ thể nhằm đạt được mục đích giao tiếp. Các kênh giao tiếp phát ra có thể là ngôn bản nói hay viết và tùy vào mục đích giao tiếp để trình bày dưới dạng 'hùng biện' như thuyết phục, mô tả, trình bày, nhân-quả, vấn đề-giải pháp, v.v. Nó liên quan đến các đặc điểm như liên kết và mạch lạc của ngôn bản - đến việc các cú được "treo" cùng nhau như thế nào để làm cho ngôn bản trở thành một thể thống nhất' (Hoàng Văn Vân, 2016). Nhìn chung, cả ba khía cạnh trong cấp độ ngôn cảnh của SFL - trường của ngôn bản, không khí của ngôn bản và phương thức của ngôn bản), đều được tóm lại trong khái niệm 'ngũ̃ vực' mà Halliday (1994) \& Halliday et al (1964) dùng để nghiên cứu về thái độ giao tiếp trong tổng hòa các mối quan hệ xã hội.

Ở cấp độ ngữ nghĩa, SFL đặt tên cho cấp độ này là 'hệ thống tạo nghĩa' (system of meaning) (Hoàng Văn Vân, 2016; Matthiessen, 1995). Khi mô tả ngôn ngữ dưới góc nhìn của cấp độ ngôn ngữ này, Halliday đã phân loại ngữ nghĩa thành ba nhóm siêu chức năng: siêu chức năng tur tuoơng (idealtional metafunction), siêu chức năng liên nhân (interpersonal metafunction), và 
siêu chúc năng ngôn bản (textual metafunction). Đặc biệt, siêu chức năng tư tưởng nhìn nhận ngữ pháp như là một cú thể hiện và được hiện thực hóa bởi hệ thống chuyển tác. Siêu chức năng này được kích hoạt bởi trường của ngôn bản ở cấp độ ngôn cảnh. Trong khi đó, siêu chức năng liên nhân coi ngữ pháp như là một cú trao đổi và được hiện thực hóa bởi hệ thống thức và tình thái. Siêu chức năng này được kích hoạt bởi không khí của ngôn bản ở cấp độ ngôn cảnh, phản ánh mối quan hệ xã hội giữa các tham thể trong hoạt động diễn ngôn. Siêu chức năng ngôn bản diễn đạt ngữ pháp như là một cú thông điệp và được hiện thực hóa bởi hệ thống đề-thuyết. Siêu chức năng này được kích hoạt bởi phương thức của ngôn bản ở cấp độ ngôn cảnh. Siêu chức năng này nêu bật được mối tương quan giữa ngôn bản và ngôn cảnh. Nói một cách khác, nó tạo ra 'sự quan yếu giữa các phần đang được nói/viết trong một thông điệp, giữa ngôn bản và ngôn cảnh (ngôn cảnh ngôn ngữ và ngôn cảnh tình huống), "thổi hơi thở của cuộc sống vào ngôn ngữ" và đem lại cho ngôn bản cảm giác thực, sự liên kết và mạch lạc' (Hoàng Văn Vân, Ibid.)

Ở cấp độ từ vựng ngữ pháp, Halliday và các nhà SFL gọi tên cấp độ này là hệ thống tạo lời (system of wording), trong đó nguồn tài nguyên từ vựng của ngôn ngữ được thể hiện dưới dạng văn bản (Halliday, 1994; Hoàng Văn Vân, 2012; Matthiessen, 1995). Ba hệ thống tạo nghĩa ở cấp độ trên trực tiếp đã kích hoạt hệ thống tạo lời từ vựng ngữ pháp ở cấp độ dưới trực tiếp. Cấp độ từ vựng và ngữ pháp giúp chúng ta hiểu được làm thế nào ngôn ngữ được mô tả và hàm ẩn ý nghĩa thông qua công cụ thước đo của hệ thống tạo lời là từ vựng và ngữ pháp. Khi mô tả ngôn ngữ ở cấp độ này, Halliday đã chỉ ra rằng tương ứng với ba nét nghĩa song song trong cấp độ ngôn cảnh - siêu chức tư tưởng, liên nhân và ngôn bản, cấp độ từ vựng ngữ pháp sẽ lần lượt được kích hoạt bằng các tiểu hệ thống tạo lời tương ứng: hệ thống chuyển tác (transitivity system), hệ thống thức (mood system), hệ thống đề ngữ (theme system). Ở cấp độ này, ngôn ngữ được thể hiện dưới dạng từ vựng, dựa vào các thành phần ngữ pháp trong cú để phản ánh kinh nghiệm (hệ thống chuyển tác), giao tiếp (hệ thống thức) và bố cục diễn ngôn (hệ thống đề ngữ). Trong nghiên cứu này, hệ thống thức sẽ được dùng chủ yếu nhằm giải thích mối quan hệ tương tác qua lại giữa bác sĩ và người bệnh thông qua việc lựa chọn thức và tình thái trong các cú. Theo Halliday \& Hasan (1976), Halliday (1979), cú có một vị trí đặc biệt trong SFL vì nằm ở giao điểm giữa ba miền: tầng bậc, cấp độ và siêu chức năng (Halliday, 1979). Mối quan hệ của cú khi đặt trong tổng thể của SFL được minh họa trong hình dưới đây.

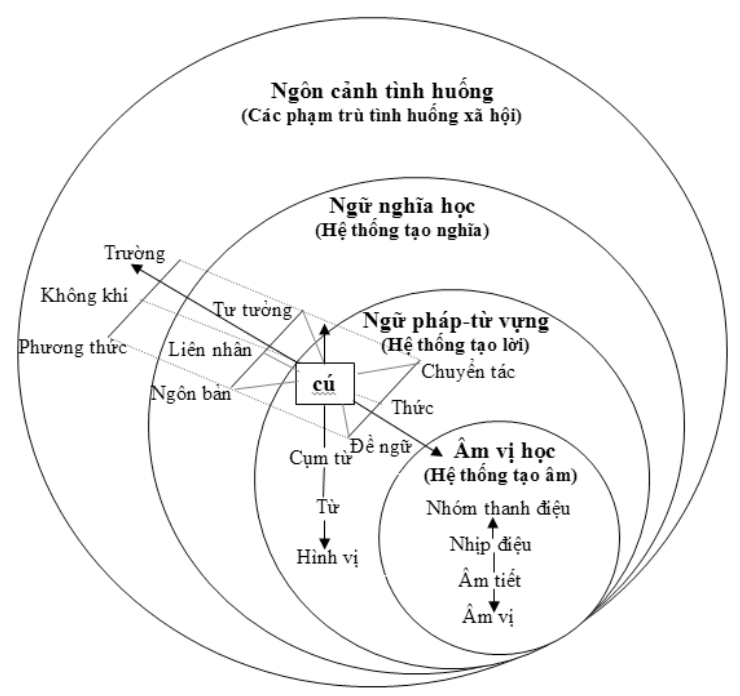

Hình 1. Vị trí của cú trong SFL

(Nguồn: Hoàng Văn Vân 2017: 30)

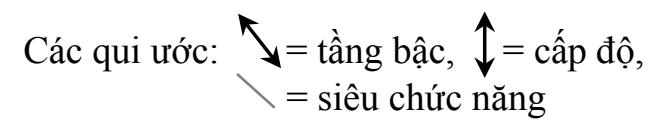

Hoàng Văn Vân (Ibid.) giải thích rằng một cú có thể thể hiện ba nét ngữ nghĩa độc lập (nghĩa biểu hiện, nghĩa trao đổi và nghĩa thông điệp). Theo đó, các cấu trúc ngôn ngữ được thể hiện dưới hệ thống chuyển tác, thức và đề ngữ cũng được kích hoạt. Đặc biệt, nhìn từ góc độ cấp độ, cú có vị trí cao nhất khi tiến hành phân tích ngữ pháp. Bên dưới cú có các thành tố, các trường từ vựng tạo nên cú. Bên 
trên cú, có các mối liên hệ liên cú, hay còn gọi là cú phức. Vì khung lý thuyết SFL ứng dụng trong nghiên cứu này để mô tả sự lựa chọn ngữ pháp và từ vựng trong ngôn từ của bác sĩ, với vị trí quan trọng của cú, nghiên cứu sẽ lựa chọn mô tả cú thông qua các mối quan hệ lôgic-ngữ nghĩa của hai hệ thống phóng chiếu và bành trướng của nguồn ẩn dụ ngữ pháp của thức và tình thái khai thác được trong lời thoại của bác sĩ tại phòng khám tư vấn.

\subsubsection{Thức và tình thái}

Thức trong SFL được liệt kê bao gồm hai tiểu thành phần là chủ ngữ (subject), là một cụm danh từ và hữu định (finite) là một phần của cụm động từ (Halliday, 2012, Hoàng Văn Vân dịch). Thành phần hữu định có thể bao gồm động từ biểu đạt thì (tense), (ví dụ, is, has) hay tình thái (ví dụ may, might). Tuy nhiên, cũng có khi thành phần hữu định và động từ lại gắn với nhau thành một từ đơn (ví dụ loves, gave). Hai tiểu thành phần của thức cho chúng ta hiểu rõ chức năng lời nói trong giao tiếp, trong khi chủ ngữ cung cấp cho chúng ta một sự phán đoán, đó là một cái gì đó qua quy chiếu của nó nhận định có thể được khẳng định hay phủ nhận; ví dụ, chủ ngữ của thức hình thành nên các cặp phân vai (người nói/người nghe hay người viết/người đọc) trong một ngôn cảnh nào đó. Chính sự phân vai diễn này cho ta hiểu được nguyên tắc trách nhiệm trong khuyến nghị, nơi mà chủ ngữ cụ thể hóa chắc năng thực sự có trách nhiệm cho việc hiện thực hóa ý nghĩa một đề nghị (offer) hay yêu cầu (command). Vậy, nghiên cứu về chủ ngữ trong đoạn thoại giữa bác sĩ và người bệnh cho ta hiểu rõ ý nghĩa của chủ thể chịu trách nhiệm với sự kiện giao tiếp khám tư vấn. Bên cạnh ý nghĩa mà sự phân tích của chủ ngữ đem lại, thành phần hữu định trong thức cũng đóng một vai trò vô cùng quan trọng vì nó có chức năng giới hạn một nhận định khi đưa nhận định trở lại thực tế bằng cách quy chiếu nó theo thời gian và không gian. Trong khi quy chiếu về thời gian là quy chiếu thời điểm nói (quy xét theo thì của động từ) thì quy chiếu về không gian là quy chiếu theo đánh giá của người nói (quy xét theo động từ tình thái). Ý nghĩa của thức không chỉ dừng lại ở sự đánh giá về chủ ngữ và hữu định, hơn thế nữa, cấu trúc của thức còn cho ta hiểu rõ chức năng lời nói của một cú là thức tuyên bố (declarative mood) (đưa ra nhận định của người nói/viết bằng cách khẳng định với người nghe/đọc về một vấn đề nào đó), thức nghi vấn (interrogative mood) (đưa ra câu hỏi của người nói/viết bằng cách yêu cầu người nghe/đọc cung cấp thông tin về một vấn đề nào đó) hay thức cầu khiến (imperative mood) (đưa ra cầu khiến của người nói/viết bằng cách yêu cầu người nghe/đọc thực hiện một vấn đề nào đó) (xem thêm Halliday, 1994; Matthiessen, 1995; Hoàng Văn Vân, 2005).

Tình thái trong SFL nằm trong hệ thống thức chỉ ra các khả năng không giới hạn trên hai phân cực (polarity) 'có' và 'không' (ví dụ tuyên bố khẳng định hay phủ định) Các cấp độ trung gian nằm giữa hai cực có thể là 'thỉnh thoảng' (sometimes) hay 'có lẽ' (maybe) (Halliday, 2012: 207, Hoàng Văn Vân dịch). Hệ thống của tình thái được Halliday (1994), Halliday và Matthiessen (2004: 619) chia làm bốn tham biến tình thái khác nhau: (i) kiểu (các đánh giá xác suất và thường lệ trong một cú 'thông tin' hay một phán đoán (propositions), đánh giá bổn phận và ý muốn trong một cú ‘hàng hóa-\&-dịch vụ’ hay một khiến nghị (proposals). Bốn kiểu tình thái này được hiện thực hóa vào hai ý nghĩa cơ bản của tình thái là tình thái hóa (modalisation) chỉ phán đoán và biến thái (modulation) chỉ khiến nghị; (ii) giá trị (đánh giá tình thái cao, trung bình, hoặc thấp); (iii) định hướng (phân biệt giữa tình thái chủ quan và khách quan) và (iv) biểu thị (phân biệt giữa tình thái hiển ngôn và ẩn ngôn).

Tóm lại, do sự giới hạn về dung lượng của một bài báo khoa học, nghiên cứu này, dựa vào khung lý thuyết của $\mathrm{CA}$ và $\mathrm{SFL}$, đã chọn lọc những cấu trúc lý thuyết có liên quan trực tiếp 
đến việc phân tích ngôn ngữ của bác sĩ tại thời điểm khám tư vấn cho người bệnh tại một vùng ngoại ô Australia. Bài báo sẽ đi theo một chiều hướng tiếp cận từ dưới lên (bottom-up approach) nhằm phân tích lượt lời (áp dụng trong $\mathrm{CA}$ ), tần số sử dụng ngữ pháp-từ vựng (thức và tình thái) (áp dụng trong SFL) để từ đó đưa ra những kết luận, giải thích sự thay đổi và lý do thay đổi trong ngôn từ của bác sĩ dưới một mô hình DTWP lấy người bệnh làm trung tâm.

\section{Các nghiên cứu có liên quan đến bài viết}

Đã có rất nhiều các công trình nghiên cứu về ngôn ngữ của bác sĩ tại phòng khám tư vấn sử dụng cách tiếp cận trong đường hướng nghiên cứu của $\mathrm{CA}$ và SFL. Phần trình bày này sẽ đề cập lần lượt lời các công trình nghiên cứu sử dụng phương pháp và thiết kế giống nhất với nghiên cứu của tác giả trong bài báo này.

Các nghiên cứu sơ khai về lời nói của bác sĩ tại phòng khám tư vấn sử dụng khung lý thuyết CA là những công trình của Frankel (1983, 1990), Heath (1982, 1986). Tiếp theo đó là các nghiên cứu về các lượt lời của Bowles (2006), Candlin (2006), Anita (2015), điều chỉnh lượt lời của Jack \& Tanya (2013), tranh lượt lời của Mishler (1984), các lượt đặt câu hỏi của Heritage (1984), Raymond (2010), Adam (2014) \& Anita (2015). Các nghiên cứu này có chung một mục đích nghiên cứu là đánh giá cách mà bác sĩ và người bệnh thể sử dụng lượt lời của mình như thế nào, ai là người sử dụng lượt lời nhiều hơn, đối tượng nào thường chêm xen vào lượt lời (Jack \& Tanya Ibid: 370, Mishler Ibid: 22), chỉnh sửa từ trong mỗi lượt lời (Jack \& Tanya Ibid: 229), đối tượng nào đặt câu hỏi nhiều hơn khi có lượt lời (Anita Ibid.) và Adam (Ibid.).

Các nghiên cứu giống với phạm vi của đề tài này khi sử dụng khung lý thuyết SFL được tiến hành không chỉ bằng tiếng Anh và còn bằng rất nhiều thứ tiếng khác nhau (Lascaratou, 2003; Hori, 2006; Overlach, 2008; Luo, 2015). Mục đích là so sánh sự giống hay dị biệt giữa ngữ vực của bác sĩ ở các vùng miền, nói các tiếng khác nhau. Tuy nhiên, các nghiên cứu này đều có chung một mục tiêu nghiên cứu đó là dựa vào từ vựngngữ pháp được sử dụng trong ngôn từ của bác sĩ để đi đến một đánh giá chung về ngữ nghĩa hàm ẩn sau lời nói. Điển hình trong nghiên cứu của Adegbite \& Odebunmi (2006) thông qua việc lựa chọn các kiểu quá trình của động từ trong lời khám tư vấn cho thấy các chiến lược lịch sự được bác sĩ thể hiện rất đa dạng. Chính các chiến lược này đã giúp cho tính tương tác giữa bác sĩ và người bệnh rất hiệu quả mặc dù tác giả vẫn tìm ra mô hình DTTP được gắn kết trong đoạn thoại đó là bác sĩ thường làm chủ các chủ đề và người bệnh là người cung cấp thông tin trong các cuộc khám. Nghiên cứu của Adam (Ibid.) cũng chỉ ra tính quyền lực của bác sĩ được thể hiện rất 'phảng phất' khi bác sĩ sử dụng thức tuyên bố có kèm theo tình thái khi muốn thương lượng với người bệnh về một phương thức điều trị. Phát hiện của Adam (Ibid.) cũng giống với Montgomery (1996: 109-110) khi tác giả này tuyên bố các phụ ngữ tình thái có thể làm giảm tính quyền lực và nâng cao tính lịch sự trong giao tiếp và thương lượng, giúp người bệnh tham gia được nhiều hơn vào quá trình giao tiếp (xem thêm Hasan 2009). Nghiên cứu của Nguyễn Thanh Nga (2017) về mối quan hệ quyền lực của bác sĩ với người bệnh trong một đoạn thoại thu được từ YouTube, tác giả đã đưa ra những dấu hiệu quyền lực được 'ngụy trang' trong chiến lược lịch sự của bác sĩ khi muốn thương thuyết với người bệnh, đó là: không sử dụng phủ định trong câu cầu khiến, câu cầu khiến ẩn dụ theo kiểu câu trần thuật chứa chủ ngữ hàm ngôn (ví dụ: tôi nghĩ là bạn nên... (I think you should...), chủ ngữ ẩn ngôn được sử dụng với số lượng lớn kèm theo tình thái (bạn có thể/nên... (you can/should) cho thấy bác sĩ muốn dịch chuyển trách nhiệm khám tư vấn sang người bệnh, muốn người bệnh làm chủ hơn trong thương lượng về phác đồ điều trị.

Các nghiên cứu trên đã đóng góp rất nhiều 
trong việc tìm hiểu ngôn ngữ của bác sĩ khi thực hiện công tác khám tư vấn. Tuy nhiên, trong nghiên cứu này, ngoài việc khảo sát tìm ra phương thức kiểm soát lượt lời và từ vựng-ngữ pháp làm kiến tạo nên sự thay đổi trong ngôn từ giao tiếp của bác sĩ dưới phương thức DTWP, tác giả còn mong muốn đưa ra những kết luận mang tính xã hội học rằng liệu ngôn ngữ của bác sĩ có bị ảnh hưởng bởi tư tưởng ngôn ngữ lấy người bệnh làm trung tâm tại Australia.

\section{Phạm vi, tiến trình và các khía cạnh phân tích số liệu}

\subsection{Phạm vi thu thập số liệu}

Số liệu được lấy trực tiếp từ một đoạn thoại tư vấn của một bác sĩ đa khoa với một bệnh nhân đến khám định kỳ. Bệnh nhân có tiền sử bị khớp gối chân mạn tính và phải tiêm thuốc 3 tháng/1 lần. Quãng giữa của mỗi đợt điều trị người bệnh thường có những biểu hiện tim đập nhanh và buồn nôn. Đoạn thoại dài 15 phút được ghi âm tại một phòng khám ở một vùng ngoại ô thủ đô Canberra, Australia. Cả bác sĩ và người bệnh đều là nam giới, cùng ở ngưỡng tuổi hơn 40. Bác sĩ đa khoa đã có thâm niên hành nghề khám tư vấn gần 20 năm. Bệnh nhân là bạn học cùng thạc sĩ ngôn ngữ với tác giả của bài báo.

\subsection{Tiến trình phân tích số liệu}

Để đảm bảo tính chính xác và giá trị của nghiên cứu, trước khi bắt đầu ghi âm, người nghiên cứu nói rõ mục đích yêu cầu của đoạn thoại cần diễn ra một cách tự nhiên và phải đảm bảo độ dài cũng như tiến trình tư vấn (mở đầu, tư vấn và kết thúc) như một cuộc khám tư vấn bình thường. Sau khi được sự cho phép của cả người bệnh và bác sĩ vào phòng khám ghi âm, vai trò của người nghiên cứu là bị động khi hoàn toàn không tham gia vào đoạn thoại. Người nghiên cứu chỉ ngồi ghi chép lại biểu hiện của gương mặt, thái độ cũng như ngôn ngữ hình thể của bác sĩ nhằm bổ trợ thêm cho phần thảo luận trong nghiên cứu. Số liệu sau đó được phiên âm lại dựa trên các ký hiệu phiên âm theo nghiên cứu của Eggins \& Slade (1997). Tuy nhiêu, tác giả loại bỏ đi những ký hiệu phiên âm không cần thiết và chỉ dùng một số các ký hiệu phục vụ cho nghiên cứu như dấu câu, các ký hiệu không phiên âm được, các ký hiệu phán đoán nội dụng nghe được hay các từ đệm, lượt lời chồng chéo. Các ký hiệu phiên âm ngữ pháp được dựa vào ký hiệu sử dụng trong Hoàng Văn Vân (2006). Sau đó số liệu được đưa vào tính máy tần số xuất hiện lượt lời cũng như đặc tính từ vựng ngữ pháp của bác sĩ và người bệnh. ${ }^{(1)}$

\subsection{Các khía canh phân tích}

Để tìm ra sự dịch chuyển ngôn ngữ của bác sĩ khi theo mô hình DTWP tại Australia, nghiên cứu này đi theo cách tiếp cận từ dưới lên đồng thời tiến hành những phân tích kết hợp định tính và định lượng như sau:

1. Phân tích định lượng tổng quát để có những số liệu cơ sở và đưa ra những kết luận chung cũng như đặt nền móng cho những bước phân tích tiếp sau đó;

2. Phân tích tỉ lệ phần trăm và đặc điểm của kiểm soát lượt lời (cặp thoại, chêm xen, chỉnh sửa), chức năng lời nói và phản ứng trong đoạn thoại;

3. Phân tích tỉ lệ phần trăm và đặc điểm của cú đơn, cú phức và liên cú trong thời nói của bác sĩ và người bệnh;

4. Phân tich tỉ lệ phần trăm và đặc điểm từ vựng và ngữ pháp thông qua sự lựa chọn của thức (cú tuyên bố, cú nghi vấn, và cú cầu khiến và của tình thái (kiểu, giá trị, định hướng và biểu thị)

\section{Kết quả và thảo luận}

\subsection{Phân tích định lượng tổng quát}

Phân tích định lượng tổng quát bao gồm việc đưa ra con số thống kê từ số khối liệu nhằm so sánh tổng quan các đơn vị so sánh

\footnotetext{
${ }^{1}$ Vì dung lượng của một bài báo khoa học có hạn, để tìm hiểu thêm thông tin chi tiết về số liệu phân tích trong bài báo, bạn đọc có thể liên hệ với tác giả qua địa chỉ email: nganguyen102005@yahoo.com
} 
giữa bác sĩ và người bệnh. Quy trình phân tích để đưa ra con số thống kê được thao tác bằng hai bước cơ bản. Thứ nhất, các đơn vị so sánh được mã hóa trong bản word (cú đơn được ký hiệu bằng hai dấu sọc đứng $\|$; cú phức bằng ba dấu sọc đứng $\|$; số lần chen lượt lời được ký hiệu là dấu bằng =); lên giọng được ký hiệu bằng mũi tên hướng lên $\uparrow)$. Thứ hai, bằng thao tác đơn giản ctrl $+\mathrm{F}$ trong chương trình Microsoft Word, tần số của đơn vị so sánh sẽ được tính. Phân tích định lượng tổng quát được minh họa trong Bảng 1 dưới đây.

Bảng 1. Số liệu định lượng tổng quát

\begin{tabular}{|c|c|c|c|}
\hline $\begin{array}{c}\text { Định lượng } \\
\text { tồng quát }\end{array}$ & Bác sĩ & Người bệnh & Tổng \\
\hline Số từ & 719 & 233 & 952 \\
\hline Số cú đơn & 157 & 63 & 220 \\
\hline Cú phức & 32 & 9 & 41 \\
\hline Lượt lời & 19 & 18 & 37 \\
\hline Chêm xen & 5 & 2 & 7 \\
\hline Chỉnh sửa & 6 & 0 & 7 \\
\hline
\end{tabular}

Bảng thống kê định lượng tổng quát cho thấy, khối ngữ liệu có tổng số từ là 952 từ, trong đó khối lượng từ bác sĩ nói ra chiếm $2 / 3$ tổng khối lượng từ trong đoạn thoại. Tổng số cú đơn trong khối ngữ liệu là 220 cú bao gồm 41cú phức, trong đó bác sĩ là người sử dụng cú phức nhiều hơn gấp 3 lần người bệnh. Tổng số lượt lời là 37 , trong đó số lần chêm xen là 7 và chỉnh sửa là 6 . Các lượt lời thể hiện rất đồng đều trong phân vai, theo mô hình bác sĩ hỏi người bệnh trả lời.

\subsection{Phân tích kiểm soát luợt lời, chức năng lời nói và phản úng}

Trong phần này, phân tích kiểm soát lượt lời theo khung lý thuyết của CA sẽ kết hợp với phân tích các chức năng lời nói (speech function) và phản ứng (responses). Theo Halliday (2012: 174) 'khởi xướng' (initiating) được phân bổ theo hàng hóa\&-dịch vụ (good-\&-services) và thông tin (information) sẽ lần lượt được khớp nối với một tập hợp các phản ứng của 'câu trả lời được đón chờ' (expected response) như 'chấp nhận', 'thực hiện', 'công nhận', 'trả lời' và 'sự lựa chọn tùy tâm' (discretionary alternative) như 'phủ nhận', 'từ chối', 'bác bỏ', 'chối'. Sự kết hợp trong phân tích kiểm soát lượt lời, chức năng lời nói và phản ứng sẽ phản ánh diễn ngôn trong cặp thoại bác sĩ-người bệnh theo chiều hướng DTWP hay DTTP. Bảng 2 chỉ ra tỉ lệ phần trăm kiểm soát lượt lời (cặp thoại, chêm xen, chỉnh sửa) và chức năng lời nói.

Bảng 2. Tần suất và tỉ lệ phần trăm kiểm soát lượt lời kết hợp chức năng lời nói

\begin{tabular}{|c|c|c|c|c|c|c|}
\hline \multirow{2}{*}{$\begin{array}{c}\text { Chức năng lời } \\
\text { nói }\end{array}$} & \multicolumn{3}{|c|}{ Bác sĩ } & \multicolumn{3}{|c|}{ Người bệnh } \\
\hline & $\begin{array}{l}\text { Tham gia } \\
\text { cặp thoại }\end{array}$ & Chêm xen & Chỉnh sửa & $\begin{array}{c}\text { Tham gia cặp } \\
\text { thoại }\end{array}$ & Chêm xen & Chỉnh sửa \\
\hline $\begin{array}{l}\text { Cho hàng hóa- } \\
\text { \&-dịch vụ }\end{array}$ & $\begin{array}{c}11 \\
(57.9 \%)\end{array}$ & 0 & 0 & $\begin{array}{c}2 \\
(11.1 \%)\end{array}$ & 0 & 0 \\
\hline Cho thông tin & $\begin{array}{c}8 \\
(42.1 \%)\end{array}$ & 7 & 0 & $\begin{array}{c}16 \\
(88.9 \%)\end{array}$ & 2 & 0 \\
\hline Tổng & $\begin{array}{c}19 \\
(100 \%)\end{array}$ & $\begin{array}{c}7 \\
(100 \%)\end{array}$ & $\begin{array}{c}0 \\
(0 \%)\end{array}$ & $\begin{array}{c}18 \\
(100 \%)\end{array}$ & $\begin{array}{c}2 \\
(100 \%)\end{array}$ & $\begin{array}{c}0 \\
(0 \%)\end{array}$ \\
\hline
\end{tabular}


Bảng 2 cho thấy tỉ lệ tần suất tham gia cặp thoại của bác sĩ và người bệnh là tương đồng, trong dịch vụ trao đổi thông tin giữa bác sĩ và người bệnh.

\begin{tabular}{|c|c|c|}
\hline (1) & $\begin{array}{l}\text { Bác sĩ: Which is ... which is a little } \\
\text { weird but it's good from ... }\end{array}$ & $\begin{array}{l}\text { Bác sĩ: Điều đó ... điều đó có thể hơi khó hiểu } \\
\text { nhung nó thưc sụ tốt nhì tù góc độ.. }\end{array}$ \\
\hline & $\begin{array}{l}\text { Nguời bệnh: = Yeah, I mean like when } \\
\text { should I be worried... }\end{array}$ & $\begin{array}{l}\text { Nguời bệnh: = Đúng rồi, nhung ý tôi muốn nói là } \\
\text { khi nào thì tôi cần bận tâm đến.... }\end{array}$ \\
\hline & $\begin{array}{l}\text { Bác sĩ: }=I \text { think you know time } \\
\text { to worried ... be if you had a lot } \\
\text { of shortness of breath. If you had } \\
\text { any chest pain you haven't had any } \\
\text { passing out episode... }\end{array}$ & $\begin{array}{l}\text { Bác sĩ: = Tôi nghĩ là bạn biết khi nào thì mới cần } \\
\text { phải bận tâm ... ví du nhu khi phát hiện thấy các } \\
\text { cơn khó thở ngắn. Hay bạn tư nhiên gặp bất cú cơn } \\
\text { đau ngục nào mà không thế có giải pháp làm thuyên } \\
\text { giảm... }\end{array}$ \\
\hline
\end{tabular}

bác sĩ chỉ hơn người bệnh một lần tham gia cặp thoại. Tuy nhiên, sự phân bổ tỉ lệ phần trăm trong chức năng lời nói có một sự khác biệt giữa bác sĩ và người bệnh. Trong khi phần lớn lượt lời của bác sĩ tham gia vào cho hàng hóa-\&-dịch vụ (57.9\%) thì chức năng lời nói của người bệnh lại thể hiện cho nhu cầu tìm kiếm thông tin, chiếm tỉ lệ phần trăm rất lớn là $88.9 \%$. Hầu hết quá trình 'chêm xen' đều do bác sĩ thực hiện, không có quá trình 'chỉnh sửa' nào xảy ra. Trong các nghiên cứu về giao tiếp bác sĩ-người bệnh, rất nhiều tác giả đã tìm ra một đặc điểm chung, bác Sĩ thường kiểm soát lượt lời với các câu hỏi (Heritage, 1984; Raymond, 2010), tham gia vào các hoạt động chêm xen, chỉnh sửa nhiều hơn người bệnh (Misler, 1984). Nghiên cứu này cũng tìm thấy sự trùng hợp với các nghiên cứu đi trước, tuy nhiên, những lần chêm xen đều rơi vào chức năng cho thông tin. Đoạn thoại trong ví dụ (1) chứng minh cho thấy sự chen lượt lời
Bác sĩ không sử dụng chức năng 'chen lượt' trong lời nói trong trao đổi 'hàng hóa-\&dịch vụ’ chứng tỏ bác sĩ khi thuyết phục hay trình bày quan điểm, ý tưởng của mình cũng rất biết lắng nghe người bệnh nói. Tuy nhiên, khi người bệnh gặp khó khăn trong việc chọn lọc thông tin để giải thích, bác sĩ sẵn sàng chia sẻ kinh nghiệm và cung cấp lời tư vấn kịp thời. Sự phân tích về lượt thoại và chêm xen trong nghiên cứu này phần nào cho thấy chiến lược tư vấn theo đường hướng DTWP của người bác sĩ.

\subsection{Phân tích cú đơn, cú phức và liên cú}

\subsubsection{So sánh cú đơn và cú phúc}

Thao tác đầu tiên trong việc phân tích cú là so sánh cú đơn và cú phức. Bảng 3 chỉ ra tỉ lệ phần trăm tần số xuất hiện cú đơn và cú phức trong giao tiếp bác sĩ và người bệnh.

Bảng 3. Cú đơn và cú phức được bác sĩ và người bệnh sử dụng

\begin{tabular}{|c|c|c|c|c|c|c|c|}
\hline \multirow{2}{*}{$\begin{array}{c}\text { Tỉ lệ phần } \\
\text { trăm }\end{array}$} & \multicolumn{3}{|c|}{ Bác sĩ } & \multicolumn{3}{|c|}{ Người bệnh } \\
\cline { 2 - 3 } & Cú đơn & Cú phức & Tổng các cú & & Cú đơn & Cú phức & Tổng các cú \\
\hline TỒNG & 157 & 32 & 189 & & 63 & 9 & 72 \\
\hline$\%$ & 83 & 17 & 100 & & 87.5 & 12.5 & 100 \\
\hline
\end{tabular}


Bảng 3 cho thấy cả bác sĩ và người bệnh sử dụng cú đơn nhiều hơn cú phức mặc dù tỉ lệ sử dụng cú phức ở bác sĩ là lớn hơn gấp 3 lần so với người bệnh. Tổng số lượng cú được bác sĩ sử dụng là 189 cú trong đó số lượng cú đơn là 157 chiếm $83 \%$ và cú phức là 32 chiếm $17 \%$. Trong khi đó, tổng số lượng cú người bệnh sử dụng là 72 , cú đơn chiếm $87.5 \%$ với 63 lần xuất hiện, gấp 7 lần so với cú phức.

So sánh việc sử dụng cú đơn và cú phức cho thấy chiến lược trong lời thoại của cả bác sĩ và người bệnh. Người bác sĩ, trong một chừng mực nào đó, sử dụng khá nhiều cú đơn khi muốn đặt những câu hỏi súc tích cho người bệnh dễ hiểu. Bên cạnh đó, bác sĩ sử dụng cú phức để mở rộng câu khi muốn giải thích hay thuyết phục người bệnh tuân theo tiến trình điều trị. Mặc dù, cũng giống như bác sĩ, người bệnh sử dụng cú đơn rất nhiều trong lời thoại nhưng cú đơn này thông thường là cú phụ (ví dụ: 'yeah', 'no', 'ok', 'sure', etc.) để đáp lại sự trưng cầu ý kiến từ bác sĩ. Tần số sử dụng cú phức của người bệnh không nhiều nhưng số lần sử dụng đa phần nhằm mô tả mức độ tuân thủ liệu trình điều trị.

\subsubsection{Phân tích liên cú}

Thao tác thứ hai trong phân tích cú là việc phân tích (i) các kiểu quan hệ phụ thuộc lẫn nhau (types of interdependency) và (ii) quan hệ logicngữ nghĩa (logico-semantic relations). Các kiểu quan hệ (i) là mối quan hệ bổ nghĩa qua đó thành phần này bổ nghĩa cho thành phần kia, không phải là một mối quan hệ duy nhất có thể thu được giữa các thành viên của cú phức. Hai thuật ngữ khái quát để chỉ mối quan hệ bổ nghĩa là phụ thuộc (Hypotaxis) và đồng đẳng (Parataxis). Phụ thuộc là mối quan hệ giữa một thành phần phụ thuộc và thành phần chi phối nó, thành phần mà nó phụ thuộc vào. Ngược lại, quan hệ đồng đẳng là quan hệ giữa hai thành phần giống nhau, thành phần này bắt đầu còn thành phần kia kế tiếp. Trong khi đó, quan hệ logic-ngữ (ii) nghĩa bao gồm một phạm vi rộng lớn các mối quan hệ logic-ngữ nghĩa khác nhau, bất kỳ mối quan hệ nào cũng đều có giá trị giữa một thành phần chính và một thành phần phụ trong mối quan hệ cú. Mối quan hệ này bao gồm hai mối quan hệ cơ bản là phóng chiếu (projection) và bành trướng (expansion). Cú phóng chiếu được hiểu đơn giản là thông qua cú chính để phát ngôn lại một lời nói hay ý tưởng nào đó. Trong khi đó cú bành trướng dựa vào ba tiểu loại là chi tiết (mang nghĩa 'bình đẳng' elaboration, ký hiệu bằng dấu=), mở rộng (mang nghĩa ‘được bổ sung vào' - expansion, ký hiệu bằng dấu + ) và tăng cường (mang nghĩa 'được nhân lên bởi’ - enhancement, ký hiệu bằng dấu x) (xem thêm Halliday 1994; Matthiessen 1995; Hoàng Văn Vân, 2012).

Phân tích liên cú cho phép hiểu sâu hơn về các kiểu quan hệ trong cú mà bác sĩ sử dụng. Tỷ lệ sử dụng cú phức của bác sĩ so với cú đơn là không cao. Tuy nhiên, vì nghiên cứu này tập trung vào lời thoại của bác sĩ, việc tìm hiểu khi nào bác sĩ sử dụng kiểu quan hệ nào trong cú, mối quan hệ logic-ngữ nghĩa của các cú phức nhằm mục đích gì đóng vai trò quan trọng trong việc diễn giải chiến lược khám tư vấn của bác sĩ dưới mô hình DTWP. Kết quả phần trăm của các tiểu loại trong các kiểu quan hệ và quan hệ logic-ngữ nghĩa được trình bày ở Bảng 4 dưới đây.

Bảng 4. Tần số sử dụng các kiểu quan hệ và quan hệ logic-ngữ nghĩa trong cú phức bác sĩ sử dụng

\begin{tabular}{|c|c|c|c|c|c|c|c|}
\hline \multirow{3}{*}{$\begin{array}{c}\text { (i) \& (ii) } \\
\text { Loại }\end{array}$} & \multicolumn{2}{|c|}{ Kiểu quan hệ (i) } & \multicolumn{5}{|c|}{ Quan hệ lôgic-ngữ nghĩa (ii) } \\
\hline & \multirow[t]{2}{*}{ Đồng đẳng } & \multirow[t]{2}{*}{ Phụ thuộc } & \multicolumn{3}{|c|}{ Bành trướng } & \multicolumn{2}{|c|}{ Phóng chiếu } \\
\hline & & & Chi tiết & Mở rộng & Tăng cường & Lời & Ý tưởng \\
\hline Tần số xuất hiện & 64 & 89 & 16 & 56 & 33 & 0 & 2 \\
\hline Tổng & \multicolumn{2}{|c|}{153} & \multicolumn{5}{|c|}{107} \\
\hline$\%$ & 41.8 & 58.2 & 14.9 & 52.4 & 30.8 & 0 & 1.9 \\
\hline
\end{tabular}


Số liệu cho thấy bác sĩ sử dụng cả hai kiểu quan hệ, tuy nhiên, tỷ lệ phần trăm trong kiểu quan hệ phụ thuộc chiếm nhiều hơn gần $1 / 3$. Trong khi đó, tiểu loại mở rộng của bành trướng phức sẽ được sử dụng dưới dạng đồng đẳng. Chiến lược này nhằm giúp cho bệnh nhân hiểu vấn đề một cách súc tích và cô đọng hơn.

\begin{tabular}{|c|c|c|}
\hline (2) & $\begin{array}{l}\| \text { I think } \| \text { you are doing great, so just .. } \| y o u \\
1.1 \quad x 1.2 \quad x 1 . \\
\text { know to keep making those lifestyle changes, } \\
\text { ||increasing your exercise. } \\
\quad x 1.4\end{array}$ & $\begin{array}{l}\text { Tôi nghĩ anh đang tuân theo quy trình } \\
\text { điều trị rất tốt vì thế chỉ cần ... anh biết } \\
\text { thay đồi lối sống, tăng cương luyện tập. }\end{array}$ \\
\hline (3) & $\begin{array}{l}\text {... } \| \text { you know } \| \text { if you'd like } \| \text { I can see you } \\
1.1 \quad x \quad 1.2 \quad x 1.3 \\
\text { back in a year just those kinds of check on things } \\
\text { |land you know feel more than welcome } \\
\quad x 2 \\
\text { to call my office. }\end{array}$ & $\begin{array}{l}\text {... anh biết không nếu anh muốn tôi } \\
\text { có thể hẹn anh gặp anh tái khám trong } \\
\text { khoảng } 1 \text { năm tới. Và sẽ thuận tiện hơn } \\
\text { nếu anh gọi điện trước đến văn phòng } \\
\text { cho tôi. }\end{array}$ \\
\hline
\end{tabular}

trong quan hệ logic-ngữ nghĩa đạt ở ngưỡng cao nhất, đối lập với tiểu loại ý tưởng của phóng chiếu không xuất hiện trường hợp nào. Việc sử dụng linh hoạt kiểu quan hệ và quan hệ logicngữ nghĩa chứng tỏ khi muốn chọn lọc sử dụng ngôn từ cho người bệnh dễ hiểu, bác sĩ thường
Trong khi đó, cú phụ thuộc, được dùng để cấp thêm thông tin cho người bệnh trong quá trình tư vấn, được bác sĩ sử dụng chủ yếu nhằm mở rộng ý kiến, giải thích hay thuyết phục người bệnh thực hiện theo lời tư vấn của mình.

\begin{tabular}{|l|l|l|}
\hline (4) & $\begin{array}{c}\| I \text { I'd like you to go to the ER } \| \text { if you have any } \\
1 \alpha\end{array}$ & $\begin{array}{l}\text { Tôi muốn anh đến tái khám ở ER nếu } \\
\text { anh có nhüng triệu chứng nhu vậy. }\end{array}$ \\
...any symptoms like that. &
\end{tabular}

sử dụng các từ kết nối từ trong cú đồng đẳng như 'so', 'but', 'and' ('vì thế, 'nhurng', 'và') hay các liên từ trong mệnh đề của cú phụ thuộc như 'as', 'because', 'which', 'when' ('khi màl lúc', 'bởi vì', 'cái mà', 'khi'). Có thể nói, kiểu quan hệ đồng đẳng hay phụ thuộc mang một ý nghĩa khác nhau trong lời nói của bác sĩ. Khi bác sĩ muốn vắn tắt hay tổng kết các bước trong tiến trình điều trị, thông thường cú trong câu
Trong quan hệ ngữ nghĩa, cú bành trướng kiểu mở rộng chiếm một số lượng lớn, tỉ lệ phần trăm tương đương với hai kiểu còn lại cùng loại là chi tiết và tăng cường. Cú bành trướng kiểu mở rộng có đặc trưng điển hình là sử dụng từ nối 'and' ('và') trong câu nhằm mang tính liệt kê, mở rộng, đôi khi thể hiện ý kiến mang tính tương đồng. Trong số 56 lấn xuất hiện của cú bành trướng kiểu mở rộng, có đến 17 lần bác sĩ sử dụng từ nối 'and'.

\begin{tabular}{|c|c|c|}
\hline (5) & $\begin{array}{r}\| \text { Well, \|he comes to the boy's hockey } \| \text { and } \\
1.1+1.2 \\
\text { his son plays in the under eight } \| \text { and I had a } \\
\text { chat to him }\end{array}$ & $\begin{array}{l}\text { À ông ấy đến chỗ bọn trẻ chơi hockey } \\
\text { và con trai ông ấy chơi trong đội lưa } \\
\text { tuổi dưới } 8 \text { và tôi đã nói chuyện với } \\
\text { ông ấy. }\end{array}$ \\
\hline
\end{tabular}


Mặc dù cú tăng cường kiểu bành trướng chỉ chiếm $33.8 \%$ trong các cú của quan hệ ngữ nghĩa, tần số sử dụng từ nối 'so' ('vì thế/vì vậy’) chỉ nguyên nhân-kết quả được bác sĩ sử dụng rất nhiều chiếm gần một nửa trong các cú tăng cường mà bác sĩ sử dụng. của bác sĩ. Toàn bộ quá trình phân tích sẽ dựa vào Halliday (1994) \& Halliday (2012).

\subsubsection{Phân tích thức}

Theo Halliday (1994: 95), phân tích về thức được dựa chủ yếu vào các cú chính hay

\begin{tabular}{|c|c|c|}
\hline (6) & $\begin{array}{l}\text { I|We allow a body mass index of up to above } \\
\qquad \begin{array}{l}1.1 \\
\text { 32, ||so you're over weight. } \\
x 1.2\end{array}\end{array}$ & $\begin{array}{l}\text { Chúng tôi cho phép chỉ số cơ thể trên } 32 \text {, } \\
\text { vì thế anh đang bị du cân đấy. }\end{array}$ \\
\hline (7) & $\begin{array}{l}\| \text { I think ||you are doing great so just .. } \| \text { you } \\
1.1 \quad x 1.2 \quad x 1.3 \\
\text { know to keep making those lifestyle changes, } \\
\text { ||increasing your exercise. } \\
\quad x 1.4\end{array}$ & $\begin{array}{l}\text { Tôi nghĩ anh đang tuân theo quy trình điều } \\
\text { trị rất tốt vì thế chì cần ... anh biết thay đồi } \\
\text { lối sống, tăng cuờng luyện tập. }\end{array}$ \\
\hline
\end{tabular}

Trong tổng các cú phức được bác sĩ sử dụng, chỉ có hai cú phóng chiếu rơi vào tiểu loại 'ý tưởng' khi bác sĩ muốn thông qua một thông điệp nào đó khẳng định thêm giá trị trong lời tư vấn của mình. Tần số xuất hiện của phóng chiếu trong khám tư vấn thường không nhiều vì đây là một hình thức giao tiếp mặt đối mặt, bác sĩ sử dụng nhiều hành động nói mang tính trực tiếp hơn gián tiếp. cú phụ mang nghĩa khẳng định hay phủ định. Trong nghiên cứu này khối ngữ liệu sẽ được phân tích theo thức tuyên bố thức cầu khiến và thức nghi vấn xét trên hai thể loại của cú là: chính và phụ. Cú chính khẳng định/phủ định sẽ bao gồm các thành phần của thức và chỉ định phân cực (xem mục 2.2.2). Thậm chí, đôi khi các thành phần của thức được giản lược đi (ví dụ Yes/No, I have/haven't). Cú phụ là các cú không có thức và có chức

\begin{tabular}{|c|c|c|}
\hline (8) & $\begin{array}{l}\| \text { So we'll just keep working on that. Luckily, } \\
1 \\
\begin{array}{r}\| \text { you know } \| \mid \text { i know } \| \text { you said } \| \text { your } \\
+2 \quad x \quad 3 \beta \quad x 3 \gamma \\
+3 \alpha \quad x \quad 3 \beta \\
\text { grandmother had }(.) \| \text { but you know } \| \text { your } \\
+4.1 \quad x 4.2\end{array} \\
\text { holter monitor is completely normal. }\end{array}$ & $\begin{array}{l}\text { Chúng ta sẽ bàn về chuyện đó nhé. Cũng } \\
\text { may anh biết đấy ... Tôi biết anh có nói là } \\
\text { bà của anh bị bệnh này, nhung anh biêt } \\
\text { đấy chỉ số của anh hoàn toàn bình thuờng. }\end{array}$ \\
\hline (9) & $\begin{array}{l}\text { ||Well, ||yeah. ||Like I said, ||you know from a } \\
1.1 \\
\text { cardiac standpoint. }\end{array}$ & $\begin{array}{l}\text { Ồ, vâng, nhu tôi đã nói với anh, anh nên } \\
\text { nhìn tù̀ góc độ về bệnh tim í. }\end{array}$ \\
\hline
\end{tabular}

\subsection{Phân tích thức và tình thái}

Mục tiêu của phân tích thức và tình thái dựa sẽ dựa vào tần số hay tỉ lệ phần trăm sử dụng thức và động từ tình thái trong lời thoại năng giống như một thành tố (ví dụ, $O K$, Well, Right, Uhm, Mmm). Chi tiết phân tích thức được biểu thị ở Bảng 5 sau đây. 
Bảng 5. Tần suất và tỉ lệ phần trăm trong việc sử dụng thức của bác sĩ và người bệnh $(\mathrm{n}=226 ; 100 \%)$

\begin{tabular}{|c|c|c|c|c|c|c|c|c|c|}
\hline \multicolumn{5}{|c|}{ Bác sĩ } & \multicolumn{5}{|c|}{ Bệnh nhân } \\
\hline & \multicolumn{2}{|c|}{ Cú chính } & \multicolumn{2}{|c|}{ Cú phụ } & & \multicolumn{2}{|c|}{ Cú chính } & \multicolumn{2}{|c|}{ Cú phụ } \\
\hline & KĐ & PĐ & $\mathbf{K Ð}$ & PĐ & & KÐ & PĐ & KÐ & PĐ \\
\hline Tuyên bố & $\begin{array}{c}128 \\
(77.1 \%)\end{array}$ & $\begin{array}{c}13 \\
(7.8 \%)\end{array}$ & 9 & 0 & Tuyên bố & $\begin{array}{c}32 \\
(53.3 \%)\end{array}$ & $\begin{array}{c}3 \\
(5 \%)\end{array}$ & $\begin{array}{c}19 \\
(31.6 \%)\end{array}$ & $\begin{array}{c}2 \\
(3.3 \%)\end{array}$ \\
\hline Nghi vấn & $\begin{array}{c}12 \\
(8.3 \%)\end{array}$ & 0 & 0 & 0 & Nghi vấn & $\begin{array}{c}4 \\
(6.6 \%)\end{array}$ & 0 & 0 & 0 \\
\hline Cầu khiến & $\begin{array}{c}4 \\
(2.7 \%)\end{array}$ & 0 & 0 & 0 & Cầu khiến & 0 & 0 & 0 & 0 \\
\hline $\begin{array}{c}\text { Tổng } \\
166(\%)\end{array}$ & $\begin{array}{c}144 \\
(86.7 \%)\end{array}$ & $\begin{array}{c}13 \\
(7.8 \%)\end{array}$ & $\begin{array}{c}9 \\
(5.5 \%)\end{array}$ & $\begin{array}{c}0 \\
(0 \%)\end{array}$ & $\begin{array}{c}\text { Tổng } \\
60(\%)\end{array}$ & $\begin{array}{c}36 \\
(60 \%)\end{array}$ & $\begin{array}{c}3 \\
(5 \%)\end{array}$ & $\begin{array}{c}19 \\
(31.7 \%)\end{array}$ & $\begin{array}{c}2 \\
(3.3 \%)\end{array}$ \\
\hline
\end{tabular}

* KĐ: khẳng định; PĐ: phủ định

Nhìn chung, cả cú chính và cú phụ khẳng định đều được bác sĩ và người bệnh sử dụng chiếm tỉ lệ phần trăm cao vượt trội. Mặc dù cú nghi vấn được sử dụng không nhiều nhưng cũng đứng ở vị trí thứ hai. Đặc biệt, cú cầu khiến chỉ được bác sĩ sử dụng chiếm tỉ lệ rất nhỏ $(2.7 \%)$.

Điều đáng chú ý là trong khi tỉ lệ cú chính tuyên bố được bác sĩ sử dụng nhiều nhất (77.1\%) thì người bệnh lại sử dụng cú phụ tuyên bố cao hơn cú phụ mà bác sĩ sử dụng (19\% so với $13 \%)$. Cú nghi vấn được bác sĩ sử dụng cao gấp 3 lần so với người bệnh và không tìm thấy cú nghi vấn phủ định trong khối ngữ liệu.

Các tỉ lệ đa dạng trong khối ngữ liệu xét từ khía cạnh phân tích thức có thể giải thích như sau. Thứ nhất, cú tuyên bố được bác sĩ sử dụng với tần suất cao vì bác sĩ có trách nhiệm phải cung cấp, giải thích thông tin cho người bệnh trong suốt cuộc thăm khám. Kết luận này cũng khá tương quan với kết luận trong phân tích liên cú (xem mục 5.3.2). Bác sĩ dùng cú tuyên bố để khẳng định, giải thích, thuyết phục người bệnh tuân theo lời tư vấn của mình. Ví dụ (10) sẽ minh họa được mục đích của cú tuyên bố trong lời thoại của bác sĩ. 


\begin{tabular}{|c|c|c|}
\hline (10) & 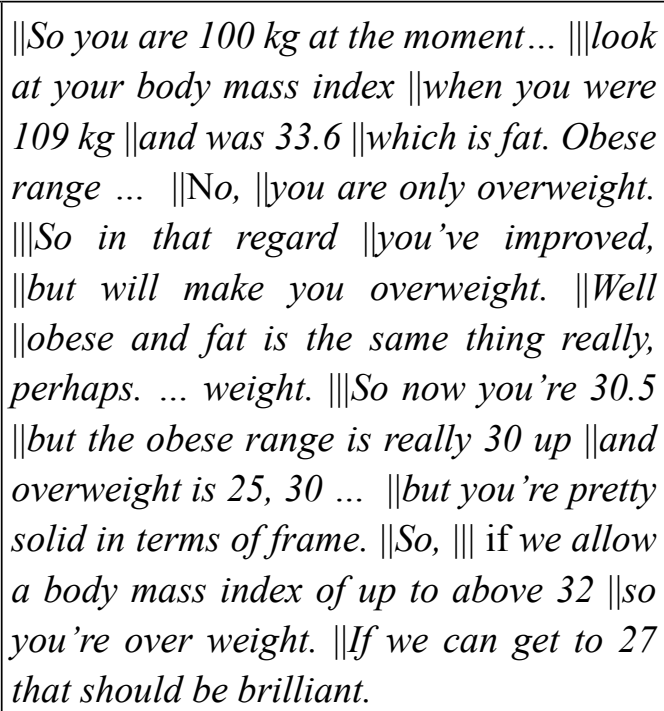 & 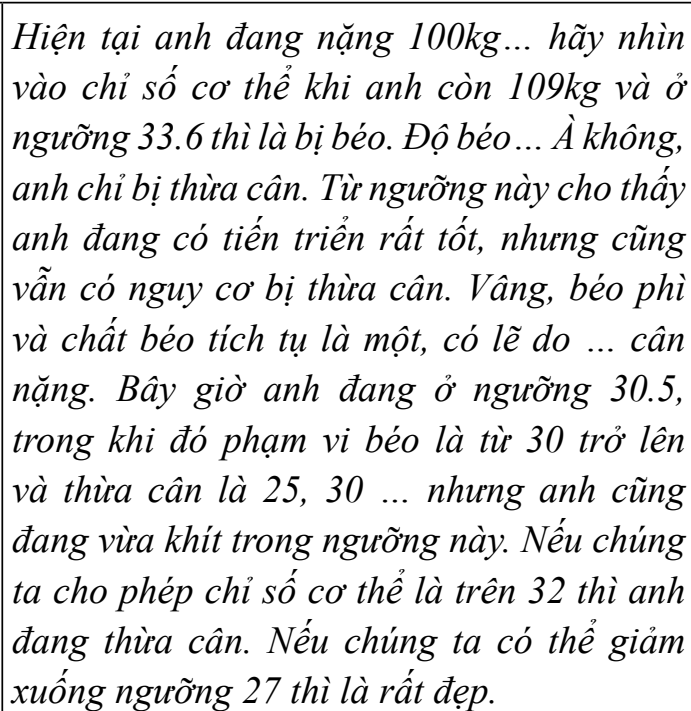 \\
\hline
\end{tabular}

Cấu trúc lời thoại khi bác sĩ sử dụng nhiều cú chính tuyên bố khẳng định - người bệnh sử dụng nhiều cú phụ tuyên bố khẳng định (ví dụ: well, ok, right, yeah) cho thấy tính tương tác khá cao trong đoạn thoại khi bác sĩ tư vấn đã nhận được phản ứng đồng phía người bệnh. Tuy nhiên, ngay trong cú nghi vấn, bác sĩ cũng sử dụng các thể loại cú nghi vấn khác nhau với các mục đich giao tiếp khác nhau. Ví dụ, khi muốn khai thác thông tin từ người bệnh, bác sĩ đặt câu hỏi có từ để hỏi (wh-questions).

\begin{tabular}{|l|l|l|}
\hline (11) & ||how much exercise are you getting?\| & Anh tập vận động nhiều thế nào? \\
\hline (12) & ||what about socially? \|what are you up to? & $\begin{array}{l}\text { Thế còn các hoạt động xã hội? Anh tham gia } \\
\text { thế nào rồi? }\end{array}$ \\
\hline
\end{tabular}

lòng từ phía người bệnh. Mặc dù, tỉ lệ phần trăm sử dụng cú phụ của bác sĩ không cao
Khi muốn người bệnh có thông tin nhanh, bác sĩ sử dụng câu hỏi phân cực.

\begin{tabular}{|l|l|l|}
\hline (13) & ||do you have any questions for me? & Anh có muốn hỏi gì không? \\
\hline (14) & ||Can I see your pulse? & Tôi xem mạch của anh được không? \\
\hline
\end{tabular}

nhưng sự khác biệt trong cách sử dụng cú phụ của bác sĩ thể hiện một ý nghĩa khác (ví dụ: great; right, fine, uhm, huh). Vì muốn người bệnh tiếp tục mô tả hay tham gia nhiều hơn nữa vào cuộc khám tư vấn nên bác sĩ đã sử dụng các cú phụ nhằm khích lệ người bệnh bày tỏ tình cảm, thái độ, cởi mở hơn trong cuộc thoại.

Thứ hai, cú nghi vấn được sử dụng chủ yếu khi bác sĩ muốn khai thác thông tin từ
Thông thường, khi một câu hỏi phân cực Có/Không được sử dụng, người nói/viết mong muốn tìm kiếm sự phản hồi đồng ý/không đồng ý từ phía người nghe/đọc. Loại câu hỏi này thường giới hạn việc trình bày phản ứng chấp thuận hay từ chối. Chính vì lẽ đó, hình thức này sẽ hạn chế tính liên nhân trong giao tiếp vì câu trả lời chỉ giới hạn ở việc chấp thuận hay không chấp thuận. Tuy nhiên, theo số liệu thu được, trong số cú nghi vấn chiếm tỉ lệ thấp, cú nghi 
vấn với câu hỏi Có/Không chỉ nêu ra được hai ví dụ trên, nghĩa là tỉ lệ phần trăm gần như bằng không. Trong nghiên cứu này, mặc dù câu hỏi Có/Không chiếm tỉ lệ không đáng kể, tuy nhiên chúng đều rơi vào nhóm câu trả lời được đón chờ một cách rõ ràng như 'of course', 'yeah' từ phía người bệnh.

Bên cạnh đó, nghiên cứu này cũng phát hiện ra, bác sĩ cũng dùng cú khẳng định, kèm theo cú phụ 'ok', 'alright' với âm điệu cao giọng cuối câu nhằm kêu gọi sự hưởng ứng hay xác nhận thông tin đồng tình từ phía người bệnh. lời thoại của bác sĩ, tác dụng của chúng cũng không hề nhỏ trong quá trình khám tư vấn. Các trường hợp sử dụng cú cầu khiến rơi vào những mục đích sử dụng sau: (i) bác sĩ yêu cầu người bệnh thực hiện thao tác đơn giản để bác sĩ khám lâm sàng cho người bệnh. (ví dụ: 'deep breath a little!'); (ii) bác sĩ không muốn có thương lượng mở với người bệnh khi muốn người bệnh có quy trình tuân thủ nghiêm ngặt. Hơn nữa, các trường hợp dùng cú cầu khiến, bác sĩ luôn kết hợp với động từ tình thái 'should', 'need' dường như với mục

\begin{tabular}{|c|c|c|}
\hline (15) & $\begin{array}{l}\| \text { So if you pass out those are things } \| \text { that ... } \\
\| \text { that would be more worrisome. } \| I \text { 'd like } \\
\text { you to go to the ER } \| \text { if you have any ... any } \\
\text { symptoms like that. OKT? }\end{array}$ & $\begin{array}{l}\text { Nếu anh bỏ qua nhũng thứ này, điều đó khá } \\
\text { là không hay. Tôi muốn anh đến tái khám ó } \\
\text { ER nếu anh có nhũng triệu chứng nhu vậy. } \\
\text { Được chứ T? }\end{array}$ \\
\hline
\end{tabular}

đích tăng thêm tính lịch sự và làm giảm nhẹ đi tính quyền lực trong lời cầu khiến cũng nhu áp lực với nguời bệnh.

(16) ||So, ||that's just from your place around. ||We all should be slim, |yyou know, |you know. |Everybody should be slim. Slim ... slim ... but of course genetic. Be more socially! You should keep moving!
Vậy có nghĩa là cũng chỉ loanh quoanh chỗ anh ở. Chúng ta ai cũng nên thon gọn, anh biết đấy. Ai cũng nên chắc khỏe. Chắc khỏe ... chắc khỏe... nhưng tất nhiên là cũng có yếu tố di truyền. Hãy tham gia nhiều hoạt động xã hội hơn. Anh nên vận động nhiều vào.
Việc dùng cú phụ khẳng định như 'ok', 'alright' không những giúp bác sĩ đón chờ sự đồng tình từ phía người bệnh mà còn giúp bác sĩ tạo điều kiện cho người bệnh có cơ hội giành lượt lời và bày tỏ ý kiến của mình.

Thứ ba, mặc dù cú cầu khiến được sử dụng với tỉ lệ thấp nhất chỉ chiếm $2.7 \%$ trong
Trong các trường hợp sử dụng cú cầu khiến, bác sĩ không dùng chúng như là một hình thức ra lệnh tách biệt. Ngược lại, cú cầu khiến luôn được dùng đan xen với cú khẳng định, hay cú phụ nghi vấn (ví dụ: 'ok T?', 'alright $\uparrow$ ?') nhằm giảm nhẹ đi tính mệnh lệnh trong lời yêu cầu.
(17) IThese parts're out on the regular rate and rather than right now. \|Take a listen to your lungs! ||Deep breath! ||Ok T? ||As long as they're clear to auscultation by that early.
Khu vục này, nhịp có vẻ không bình thuờng và có vẻ ngay lúc này đang có vấn đề rồi. Nghe phổi nào! Hit sâu! Ổn không T?Để đến khi nghe phổi được rõ hơn đã. 
Tại các trường hợp thăm khám tư vấn, thông thường bác sĩ luôn là người nắm vị trí chủ động trong suốt cuộc khám vì họ đóng vai trò đại diện cho việc thực hiện nhiệm vụ y tế, gánh vác trách nhiệm chủ chốt cho sức khỏe của người bệnh. Chính vì lẽ đó, bác sĩ hóa (modalisation) chỉ phán đoán và biến thái (modulation) chỉ khiến nghị được chấp nhận làm khung lý thuyết trong nghiên cứu này (xem lại mục 2.2.2). Trước hết, chi tiết phân tích bốn kiểu tình thái gắn với giá trị tình thái được biểu thị ở Bảng 6 dưới đây.

Bảng 6. Tần số và tỉ lệ (\%) của kiểu tình thái gắn với giá trị được bác sĩ và người bệnh sử dụng

\begin{tabular}{|c|c|c|c|c|c|c|c|c|c|}
\hline & & \multicolumn{4}{|c|}{ Bác sĩ } & \multicolumn{3}{|c|}{ Người bệnh } & \\
\hline \multirow{2}{*}{\multicolumn{2}{|c|}{ Các tham biến }} & \multicolumn{7}{|c|}{ Giá trị** } & \\
\hline & & $\mathbf{C}$ & TB & $T$ & Tổng & C & TB & $\mathbf{T}$ & Tổng \\
\hline \multirow{2}{*}{$\begin{array}{l}\text { Tình thái hóa } \\
\text { (thông tin) }\end{array}$} & Xác suất & & 7 & 10 & $\begin{array}{c}17 \\
(21 \%)\end{array}$ & 0 & 3 & 0 & 3 \\
\hline & Thường lệ & 6 & 5 & 1 & $\begin{array}{c}12 \\
(14.8 \%)\end{array}$ & 0 & 0 & 0 & 0 \\
\hline \multirow{2}{*}{$\begin{array}{l}\text { Biến thái } \\
\text { (hàng hóa-\& } \\
\text {-dịch vụ) }\end{array}$} & $\begin{array}{c}\text { Bổn phận (không } \\
\text { biến điệu) }\end{array}$ & 2 & 4 & 1 & $\begin{array}{c}7 \\
(8.7 \%)\end{array}$ & 0 & 0 & 0 & 0 \\
\hline & $\begin{array}{c}\text { Ý muốn } \\
\text { (biến điệu) }\end{array}$ & 6 & 11 & 24 & $\begin{array}{c}41 \\
(50.5 \%)\end{array}$ & 0 & 1 & 0 & 1 \\
\hline Tổng : & $81(100 \%)$ & $\begin{array}{c}14 \\
(17.2 \%)\end{array}$ & $\begin{array}{c}27 \\
(33.3 \%)\end{array}$ & $\begin{array}{c}36 \\
(44.5 \%)\end{array}$ & $\begin{array}{c}77 \\
(95 \%)\end{array}$ & $\mathbf{0}$ & $\begin{array}{c}4 \\
(5 \%)\end{array}$ & $\mathbf{0}$ & $\begin{array}{c}4 \\
(5 \%)\end{array}$ \\
\hline
\end{tabular}

* C: Cao; TB: Trung bình; T: Thấp

thường hay thể hiện tính quyền lực rất cao đối với người bệnh. Tuy nhiên, nghiên cứu này cho thấy, bác sĩ đã thể hiện quyền lực theo một phương thức khác khi theo mô hình khám DTWP lấy người bệnh làm trung tâm. Sự phân tích thức cho thấy cú cầu khiến được bác sĩ sử dụng mang ý nghĩa như là sự hướng dẫn, lời khuyên chứ không phải yêu cầu hay ra lệnh.

\subsubsection{Phân tích động tù̀ tình thái}

Theo Halliday (1994: 81-83), dưới hệ thống của thức, động từ tình thái có thể được sắp xếp, chia theo các tiểu mục của phụ ngữ tình thái (mood adjuncts) như 'cực' (polarity), 'tình thái' (modality) 'thời gian' (temporarility), và 'thức' (mood). Vì giới hạn của đề tài, chỉ có bốn tham biến tình thái được hiện thực hóa vào hai ý nghĩa cơ bản của tình thái là tình thái
Bảng 6 chỉ ra tổng tỉ lệ phần trăm của việc sử dụng các tác tử tình thái (modal operators) gắn với các tham biến được bác sĩ và người bệnh sử dụng. Có thể thấy bác sĩ sử dụng tình thái nhiều hơn vượt trội (chiếm 95\%) so với người bệnh (chiếm 5\%). Việc sử dụng các tác tử tình thái trong ngôn từ của bác sĩ được phân bổ rải rác trên tất cả các tham biến, đặc biệt tham biến 'biến thái' (hàng hóa-\&-dịch vụ) chiếm nhiều tỉ lệ phần trăm nhiều sấp xỉ gấp đôi so với tham biến 'tình thái hóa' (thông tin). Các tác tử tình thái 'xác suất' như will/ may/might và 'ý muốn' need/will/would/should/can được sử dụng nhiều hơn so với hai loại tình thái còn lại là 'thường lệ' always/usually/sometimes và bổn phận have to. Đặc biệt, tình thái 'ý muốn' được sử dụng với tỉ lệ phần trăm rất 
cao, chiếm $50.5 \%$ trong các tham biến tình thái mà bác sĩ sử dụng. Bên cạnh đó, giá trị tình thái trong lời nói của bác sĩ rơi vào ngưỡng giá trị thấp nhiều nhất, chỉ có $14 \%$ rơi vào ngưỡng cao như always/have to/ need/needn't. Điều này chứng tỏ, bác sĩ sử dụng chiến lược lấy người bệnh làm trung tâm khi bác sĩ chú trọng vào việc giải thích, thuyết phục và nói chuyện với người bệnh nhiều hơn là cung cấp thông tin. Các cú trong trao đổi 'hàng hóa-\&-dịch vụ' thường gắn kết với các tác tử tình thái như là một công cụ giúp tạo lòng tin cho người bệnh khi nghe bác sĩ giải thích và thuyết phục. Nếu các tình thái này không được sử dụng, lời thoại của bác sĩ sẽ trực tiếp, không biến điệu, hiển nhiên sẽ khó khăn hơn trong việc thuyết phục người bệnh đồng ý và thỏa mãn với những thông tin hay lời khuyên tư vấn từ phía bác sĩ.

\begin{tabular}{|l|l|l|l|}
\hline (18) & $\begin{array}{l}\text { We all should } \\
\text { be slim, you } \\
\text { know, you know. }\end{array}$ & $\begin{array}{l}\text { Chúng ta ai cũng } \\
\text { nên săn chắc, anh } \\
\text { biết đấy, anh biết } \\
\text { đấy }\end{array}$ \\
\hline
\end{tabular}

Mặc dù được sử dụng với tỉ lệ phần trăm it hơn nhưng các tác tử tình thái trong tham biến 'tình thái hóa' nhằm cung cấp thông tin cũng chiếm một vị trí rất quan trọng trong lời nói của bác sĩ khi mong muốn cho người bệnh hiểu rõ tình trạng sức khỏe của mình. trong lời nói mà bác sĩ phán đoán, ví dụ (10), 'would' được dùng để giảm nhẹ nỗi lo cho người bệnh trong lời cảnh báo của bác sĩ.

Khi các tác tử tình thái trong tham biến 'ý muốn' ở giá trị thấp như 'need', 'will', 'should', 'can' và 'may' được sử dụng nhiều hơn 'bổn phận' đóng vai trò quan trọng trong việc thuyết phục người bệnh tuân theo hoạt động tư vấn của bác sĩ. Tác tử tình thái 'bổn phận' cho phép bác sĩ vừa thực hiện trách nhiệm của mình được dễ dàng, vừa tránh sử dụng cú cầu khiến mang tính trực tiếp.

\begin{tabular}{|c|c|c|}
\hline (21) & $\begin{array}{l}\||| \text { don't think } \\
\| \text { we need to } \\
\text { start with any } \\
\text { medications. }\end{array}$ & $\begin{array}{l}\text { Tôi không nghĩ chúng } \\
\text { ra cần phải bắt đầu } \\
\text { với việc dùng bất cú } \\
\text { loại thuốc gì }\end{array}$ \\
\hline (22) & $\begin{array}{l}\|\| \text { If we can } \\
\text { get to } 27 \| \text { that } \\
\text { should be } \\
\text { brilliant. }\end{array}$ & $\begin{array}{l}\text { Nếu chúng ta có thể } \\
\text { giảm xuống ngương } \\
27 \text { thì là rất đẹp. }\end{array}$ \\
\hline
\end{tabular}

Halliday (1994: 357-358) cho rằng trong bốn tham biến tình thái, tình thái 'định hướng' đóng vai trò đặc trưng trong việc xác định mỗi một tác tử tình thái mang ý nghĩa gì. Trong khi đó tình thái 'biểu thị' đưa ra phạm trù 'hiển ngôn' (explicit) và 'ẩn ngôn' (implicit) được hiện thực hóa vào hai khái niệm 'chủ quan' (subjective) và 'khách quan' (objective). Halliday (Ibid.) giải thích rằng nhìn từ góc độ

\begin{tabular}{|c|c|c|}
\hline (19) & $\begin{array}{l}\| \text { So in that regard you've improved } \| \text { but that } \\
\text { will make you overweight. }\end{array}$ & $\begin{array}{l}\text { Tù ngương này cho thấy anh đang có tiến } \\
\text { triến rất tốt, nhung cũng vẫn sê có nguy } \\
\text { co bị thù̃ a cân. }\end{array}$ \\
\hline (20) & $\begin{array}{l}\text { \|So if you pass out those are things that ... } \\
\| \text { that would be more worrisome. I|I'd like } \\
\text { you to go to the ER \|if you have any ... any } \\
\text { symptoms like that. }\end{array}$ & $\begin{array}{l}\text { Nếu anh bỏ qua những thứ này, điều đó } \\
\text { sẽ khá là không hay. Tôi muốn anh đến } \\
\text { tái khám ổ ER nếu anh có những triệu } \\
\text { chứng nhu vậ. Đuợc chứ t? }\end{array}$ \\
\hline
\end{tabular}

Có thể nói, hai tác tử tình thái 'will' và 'would', thuộc tham biến xác suất trong hai ví dụ trên đã phục vụ việc cung cấp thông tin với các mục đích khác nhau. Khi ví dụ (9) tác tử tình thái 'will' được dùng như để khẳng định đánh giá hiển ngôn, hiển ngôn chủ quan được thể hiển bằng 'cảm thể' (Sensor) - 'Tôi' (I) + kiểu quá trình 'tinh thần' (mental processes) như think, wish, understand (ví dụ: I think/ wish/understand); hiển ngôn khách quan được 
hiện thực hóa vào các cú phóng chiếu như (it's likely...). Trong khi đó, đánh giá ẩn ngôn không đại diện trách nhiệm cho người nói/viết mà trao cho người nghe/đọc trong quá trình tương tác. Ẩn ngôn chủ quan được hiện thực hóa bởi các tác tử tình thái như may, will, should (vi dụ: you may/will/ should); ẩn ngôn khách quan được gắn với các phụ ngữ chỉ thức như really, luckily, completely, likely. Vậy khi phân tích về sự kết hợp 'kiểu tình thái' và tham biến ‘định hướng', nghiên cứu này chỉ rõ chiến lược khám bệnh lấy người bệnh làm trung tâm của người bác sĩ. Bảng 7 dưới đây thống kê tần suất và tỉ lệ phần trăm của hiển ngôn/ẩn ngôn khi nhập mã chủ quan hay khách quan trong lời nói của bác sĩ.

\begin{tabular}{|l|l|l|}
\hline (23) & $\|$ And you know $\|$ as & Và anh biết đấy, \\
& long as you can do & ngay khi anh có \\
anything else come & thể làm cho mọi \\
up. $\| I$ will see you & việc có tiến triên \\
back here. & tôt. Tôi sẽ hẹn \\
& gặp anh ở đây. \\
\hline
\end{tabular}

Việc bác sĩ sử dụng nhiều chủ quan ẩn ngôn cho thấy chiến lược khám tư vấn lấy người bệnh làm trung tâm được thể hiện bằng việc bác sĩ luôn chú ý gắn kết ngôn từ của mình hướng tới người bệnh, nâng cao tính tự chủ của người bệnh. Bằng cách đó, người bệnh không bị thụ động mà ngược lại chủ động đóng góp ý kiến trong quá trình điều trị.

Tuy nhiên để làm tốt nhiệm vụ chức trách

Bảng 7. Tham biến ‘định hướng’ và 'biểu thị’ kết hợp tình thái được bác sĩ sử dụng

\begin{tabular}{|c|c|c|}
\hline \multicolumn{1}{|c|}{ Bị̂nh hướng thị } & Tần số & Tỉ lệ phần trăm \\
\hline Chủ quan: hiển ngôn & 7 & $12.3 \%$ \\
\hline Chủ quan: ẩn ngôn & 35 & $61.4 \%$ \\
\hline Khách quan: hiển ngôn & 2 & $3.5 \%$ \\
\hline Khách quan: ẩn ngôn & 13 & $22.8 \%$ \\
\hline Tổng & $\mathbf{5 7}$ & $\mathbf{1 0 0 \%}$ \\
\hline
\end{tabular}

Bảng 7 cho thấy, trong số 57 cú có chứa đánh giá diễn đạt khả năng xác suất đa phần đều nhập mã chủ quan (chiếm hơn $70 \%$ ). Ngược lại, đánh giá khách quan chiếm tỉ lệ thấp, đặc biệt khách quan hiển ngôn chỉ đạt ngưỡng $3.5 \%$.

Đánh giá chủ quan ẩn ngôn, chiếm tỉ lệ cao nhất, được hiện thực hóa với các chủ ngữ chỉ người bệnh - 'you' + các tác tử tình thái như can, may, should, với mong muốn người bệnh chủ động hơn trong quá trình điều trị. của mình, bác sĩ cũng sử dụng đánh giá chủ quan hiển ngôn với cấu trúc điển hình I know/ think/understand nhằm vừa nhấn mạnh ý kiến hay lời khuyên, vừa thể hiện tình cảm của mình đối với người bệnh.

\begin{tabular}{|l|l|l|}
\hline (24) & || So I think & Tôi nghĩ là... anh \\
.. Ilyou know & nên nhìn mọi thú \\
e ve er y th i n g & bình thưòng tù góc \\
& |llooks normal & độ về bệnh tim i. \\
from cardiology & \\
& standpoint. & \\
\hline
\end{tabular}

Tỉ lệ kết hợp hài hòa trong việc sử dụng đánh giá chủ quan ẩn ngôn và hiển ngôn của bác sĩ cho thấy khi mong muốn dịch chuyển 
tính trách nhiệm, nâng cao tính tự chủ cho người bệnh bác sĩ sử dụng chủ quan ẩn ngôn, khi cần nhấn mạnh quan điểm của mình, bác sĩ chuyển sang sử dụng chủ quan hiển ngôn nhằm chia sẻ kinh nghiệm, tạo niềm tin hơn cho người bệnh. Bằng cách này, bác sĩ đã không tạo áp lực cho người bệnh mà ngược lại thúc đẩy được tính độc lập, tự chủ cho người bệnh, tạo cho người bệnh một bầu không khí hợp tác trong suốt cuộc khám tư vấn.

Tỉ lệ phần trăm thấp trong đánh giá khách quan hiển ngôn cho thấy bác sĩ tự tin với những nhận định của mình hơn là dựa vào các ý kiến phản hồi hay kinh nghiệm từ bên ngoài. Điều này cũng hoàn toàn dễ hiểu vì bác sĩ là người có kinh nghiệm khám tư vấn hơn 20 năm, chính vì thế việc thể hiện kiến thức, kinh nghiệm thực tế của bản thân thu thập được sẽ mang lại hiệu quả, tạo lòng tin trước người bệnh nhiều hơn.

Đánh giá khách quan ẩn ngôn chiếm tỉ lệ phần trăm cao thứ hai trong nghiên cứu này, và chúng được hiện thực hóa vào các phụ ngữ của thức (ví dụ: really, luckily, completely, likely). Theo Halliday và Matthiessen (2004: 129), kiểu đánh giá mô tả được thái độ của người nói/viết trong chức năng lời nói. Nghiên cứu này chỉ ra được các đánh giá khách quan ẩn ngôn được hiện thực hóa trong các cú tuyên bố giúp bác sĩ chia sẻ quan điểm, kế hoạch điều trị trước bệnh nhân, giảm thiểu đi phương thức nói mang tính cầu khiến trực tiếp mà vẫn làm chủ được trong suốt cuộc khám tư vấn.

\begin{tabular}{|c|c|c|}
\hline (25) & 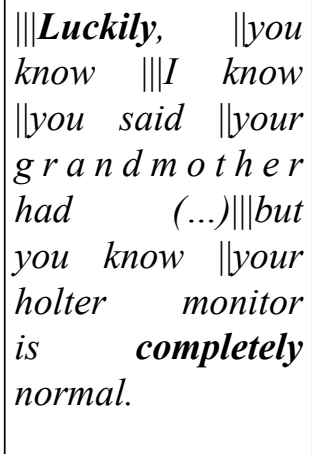 & $\begin{array}{l}\text { Cũng may anh } \\
\text { biết đấy ... Tôi } \\
\text { biết anh có nói } \\
\text { là bà của anh bị } \\
\text { bệnh này, nhung } \\
\text { anh biết đấy } \\
\text { chì số của anh } \\
\text { hoàn toàn bình } \\
\text { thuòng. }\end{array}$ \\
\hline
\end{tabular}

Tỉ lệ phân bố đánh giá hiển ngôn và ẩn ngôn nhập mã trong chủ quan và khách quan cho thấy bác sĩ đã áp dụng chiến lược lấy người bệnh làm trung tâm với những dấu hiệu chuyển dịch trách nhiệm và tự chủ cho người bệnh. Bên cạnh đó để làm tốt nhiệm vụ của mình, bác sĩ chia sẻ kiến thức, kinh nghiệm, quan điểm trước người bệnh nhằm tạo dựng một bầu không khí tương tác trong suốt quá trình giao tiếp với người bệnh khám tư vấn.

\section{Kết luận}

Nghiên cứu này khảo sát sự kiểm soát lượt lời trong khung lý thuyết của $\mathrm{CA}$ và các đặc tính ngữ pháp của thức (thức và tình thái) trong khung lý thuyết của SFL để chứng minh những dấu hiệu của sự dịch chuyển ngôn ngữ khám tư vấn của bác sĩ theo mô hình khám tư vấn DTWP được nhân rộng ở Australia. Thực tế, Aichison (2000: 3) đã giải thích 'language, like everything else is joining in the general flux' (tạm dịch là: 'ngôn ngữ, cũng như nhiều vạn vật khác đang tham gia vào dòng chảy chung'). Điều này có nghĩa ngôn ngữ không bao giờ ‘đứng yên', ngược lại, ngôn ngữ luôn chuyển động. Hay khi nhấn mạnh sự dịch chuyển ngôn ngữ theo chiều hướng 'thân thiện' (informality) tại Australia, Jones (2006: 6) đã viết: "a vast number of societies have been undergoing an inexorable movement towards informality in the use of language: it is part of the 'ever-whirling wheel' of linguistic evolution that some deplore as a form of decadence and others accept as being inevitable and natural" (tạm dịch là: Nhiều phạm trù xã hội khác nhau đã và đang trải qua một sự dịch chuyển trong việc sử dụng ngôn ngữ theo chiều hướng 'thân thiện' hơn: đây chính là một quá trình phát triển 'không ngừng nghỉ' của ngôn ngữ mà một số trường phái cho rằng đó là sự suy đồi, một số khác thì lại chấp nhận đó là sự thay đổi trong vòng xoay phát triển tự nhiên của ngôn ngữ.). Dù sao, có rất nhiều cách đưa ra những bằng chứng về sự thay đổi diễn ngôn trong tư vấn khám chữa 
bệnh, tuy nhiên vì sự giới hạn không gian của một bài báo khoa học, nghiên cứu này chỉ dừng lại ở việc đưa ra những minh chứng về hoạt động kiểm soát lượt lời và một số đặc điểm ngữ pháp-từ vựng đã hình thành phương thức khám tư vấn theo mô hình DTWP của bác sĩ tham gia nghiên cứu. Có thể tóm tắt các bằng chứng tạo ngôn của bác sĩ dưới mô hình lấy người bệnh làm trung tâm như sau.

Bà̀ng chứng về kiểm soát lượt lời, chức năng lời nói và phản úng

Tỉ lệ ngang bằng khi tham gia cặp thoại giữa bác sĩ và người bệnh, kiểm soát lượt lời như chem xen chiếm số lượng không nhiều và nếu có chỉ là bác sĩ muốn cung cấp thông tin, hay mở rộng lời tư vấn khi người bệnh không hiểu rõ một vấn đề trong tiến trình tư vấn. Tỉ lệ nghịch về chức năng lời nói giữa bác sĩ và người bệnh thể hiện bác sĩ sử dụng nhiều vai diễn cho 'hàng hóa-\&-dịch vự' còn bệnh nhân cho 'thông tin'. Không phát hiện thấy chức năng lời nói mang ý nghĩa chen lượt nào xuất hiện.

Bà̀ng chứng về việc sủ dụng cú đon, cú phức và liên cú

Cả bác sĩ và người bệnh sử dụng cú đơn nhiều hơn cú phức. Cú đơn được bác sĩ sử dụng nhiều khi muốn đặt những câu hỏi súc tích, hay đưa ra những câu cầu khiến ngắn gọn. Trong khi đó, cú phức, mặc dù chiếm tỉ lệ không cao so với cú đơn ở cả bác sĩ và người bệnh, nhưng bác sĩ dùng nhiều cú phức hơn trong các trường hợp muốn mở rộng câu để giải thích hay thuyết phục người bệnh tuân theo quy trình điều trị. Cú đơn được bệnh nhân sử dụng phần nhiều là cú phụ để bày tỏ thái độ đồng ý hay không đồng ý với lời tư vấn của bác sĩ.

Phân tích các kiểu quan hệ cho thấy khi bác sĩ dùng cú đồng đẳng khi tư vấn cho người bệnh các bước trong tiến trình điều trị, diễn ngôn của bác sĩ hướng tới sự đơn giản, cô đọng và súc tích, giúp người bệnh dễ hiểu. Tuy nhiên khi muốn cung cấp thông tin hay mở rộng lời giải thích, bày tỏ ý kiến nhằm thuyết phục người bệnh, bác sĩ dùng cú phụ thuộc.

Phân tích quan hệ lô-gic ngữ nghĩa cho thấy cú bành trướng kiểu mở rộng chiếm số lượng 50\% so kiểu chi tiết và tăng cường. Bác sĩ sử dụng cú mở rộng với liên từ 'and' mang ý nghĩa liệt kê hoặc chỉ cụm từ/ngữ đồng nghĩa. Bằng cách đó, lời nói của bác sĩ rõ ràng và dễ hiểu hơn. Bên cạnh đó, cú tăng cường kiểu bành trướng với liên từ 'so' chiếm vị trí thứ hai có chức năng chỉ nguyên nhân và kết quả, đặc biệt rất quan trọng trong công tác khám tư vấn vì người bệnh luôn cần bác sĩ cung cấp thông tin về nguyên nhân gây bệnh hay kết quả của liệu trình chữa bệnh. Cú phóng chiếu không được sử dụng nhiều, chiếm tỉ lệ rất thấp và bác sĩ chỉ dùng khi muốn thông qua một thông điệp, lời nói của một ai đó để khẳng định thêm giá trị lời tư vấn của mình.

\section{Bằng chứng về việc sử dụng thức và tình thái}

Đối với việc sử dụng thức, cú chính và cú phụ khẳng định được cả bác sĩ và người bệnh sử dụng nhiều nhất, sau đó đến cú nghi vấn và tỉ lệ thấp nhất là cú cầu khiến, đặc biệt không phát hiện cú cầu khiến phủ định. Cú chính khẳng định được bác sĩ sử dụng với tần suất cao vì trong suốt cuộc khám tư vấn, bác sĩ là người thi hành trách nhiệm của một cán bộ y tế, vì vậy bác sĩ phải cung cấp, giải thích, thuyết phục người bệnh. Trong khi đó, người bệnh dùng cú phụ khẳng định cao hơn so với bác sĩ cho thấy tỉ lệ hài lòng của người bệnh khá lớn. Cú phụ phần lớn được bác sĩ sử dụng để khuyến khích người bệnh nói và trả lời câu hỏi của bác sĩ. Bên cạnh đó, cú nghi vấn được bác sĩ dùng để khai thác thông tin, hay cũng có khi cú nghi vấn là biến thái của cú khẳng định với cú phụ như 'ok $\uparrow$ ', 'alright $\uparrow$ ' được lên giọng ở cuối câu nhằm kêu gọi sự đồng tình của người bệnh. Cú cầu khiến không được sử dụng nhiều, nếu có rơi vào hai trường hợp là (i) bác sĩ yêu cầu người bệnh thực hiện một động tác trong khi khám bệnh; (ii) bác sĩ muốn người bệnh 
tuân theo quy trình khám bệnh nghiêm ngặt và không bày tỏ thương lượng mở.

Đối với việc sử dụng tình thái, bác sĩ sử dụng tình thái chiếm tỉ lệ vượt trội. Các tác tử tình thái trong ngôn từ của bác sĩ được phân bổ rải rác trên tất cả các tham biến, đặc biệt tham biến 'biến thái' (hàng hóa-\&-dịch vụ) chiếm nhiều tỉ lệ phần trăm nhiều xấp xỉ gấp đôi so với tham biến 'tình thái hóa' (thông tin). Các giá trị của tình thái khi gắn kết với các tham biến thường ở mức thấp. Các tham biến tình thái 'định hướng' và 'biểu thị' nhập mã chủ quan chiếm tỉ lệ cao, đặc biệt là chủ quan ẩn ngôn được hiện thực hóa với chủ ngữ chỉ người bệnh 'you'. Điều này chứng tỏ bác sĩ luôn đặt người bệnh vào vị trí trung tâm trong diễn ngôn của mình. Tỉ lệ khách quan ẩn ngôn chiếm vị trí tương đối cao trong lời nói của bác sĩ đóng một chức năng giảm thiểu phương thức cầu khiến trực tiếp.

Từ kết quả của nghiên cứu, bài báo đưa ra một số kết luận như sau:

Thứ nhất, lời nói của bác sĩ khi giao tiếp với người bệnh tại phòng khám đã chứng minh sự dịch chuyển diễn ngôn theo đường hướng DTWP trong tư vấn khám chữa bệnh. Cụ thể, việc phân tích quá trình kiểm soát lượt lời và các đặc tính từ vựng-ngữ pháp của thức và tình thái cho thấy bác sĩ đã khai thác rất hiệu quả nguồn tài nguyên ngữ pháp trong ngôn từ của mình để vừa nâng cao được tính độc lập, tự chủ cho người bệnh vừa thể hiện tính quyền lực lịch sự khi luôn hướng tời người bệnh, lấy người bệnh làm trung tâm. Nói một cách khác, để làm tròn trách nhiệm của mình, ẩn sau ngôn từ của bác sĩ là một phương châm giao tiếp lịch sự, gần gũi và thân thiện.

Thứ hai, các nguồn tài nguyên về ngữ pháp có đóng góp rất lớn trong việc nâng cao chất lượng lời nói của bác sĩ khi giao tiếp với người bệnh đặc biệt là việc sử dụng hiệu quả kiểm soát lượt lời, câu phức, chủ ngữ hay tình thái trong ngôn từ.
Thư $b a$, ngôn ngữ của bác sĩ không thể ‘đứng yên' khi nó nằm trong một hệ thống ngôn ngữ của xã hội mà nó thuộc về. Cụ thể, ngôn ngữ của bác sĩ trong nghiên cứu đương nhiên chịu ảnh hưởng trực tiếp của hệ thống ngôn ngữ ở Australia luôn được thay đổi để hướng tới tính gần gũi và thân thiện (Jones, 2004: 6).

Mặc dù nghiên cứu này chỉ khảo sát trên phạm vi hẹp về kiểm soát lượt lời, cách sử dụng thức và tình thái trong khung lý thuyết của SFL nhưng đây cũng là một sự khẳng định về tính hiệu quả và giá trị nhân văn của hình thức khám chữa bệnh lấy người bệnh làm trung tâm - DTWP. Nghiên cứu cũng là một lời kêu gọi trong việc thay đổi trong diễn ngôn của bác sĩ nên hướng tới tính lịch sự, ân cần, hay nói như Roter \& Hall (1992: 8-9), bác sĩ nên coi người bệnh là một 'chuyên gia' ('experts') bởi vì trong khi bác sĩ chỉ dựa vào 'chỉ số bệnh lý' (medical data), người bệnh có một cái nhìn tổng quan về sức khỏe của chính mình về cả thể trạng và nội tâm. Hy vọng bài báo này không chỉ đóng góp cho những cá nhân hay cơ quan nghiên cứu về ngôn ngữ nói chung mà còn là một tư liệu quý báu cho các sinh viên y khoa tham khảo, trau dồi $\mathrm{y}$ đức, rèn luyện phương thức giao tiếp với người bệnh đạt hiệu quả cao.

\section{Tài liệu tham khảo}

\section{Tiếng Việt}

Halliday, M. A. K, (2012). Dẫn luận ngũ pháp chức năng (2 $2^{\text {nd }}$ ed). Hoàng Văn Vân dịch. Hà Nội: NXB ĐHQGHN.

Hoàng Văn Vân (2005). Ngũ pháp kinh nghiệm của cú tiếng Việt: Mô tả theo quan điểm chức năng hệ thống. In lần thứ hai. Hà Nội: Nxb. Khoa học Xã hội.

Hoàng Văn Vân (2016). Tiếng Việt khoa học trong sách giáo khoa phổ thông: Khảo sát đặc điểm ngũ̃ pháptừ vựng của 7 bài học trong Sinh học 8 từ bình diện chuyển tác. Ngôn ngũu, 6(325), trang 11-31.

Hoàng Văn Vân (2017). Ngôn ngữ của sách giáo khoa phổ thông: Khảo sát đặc điểm ngữ pháp-từ vựng của 7 bài học (ngôn bản) trong Sinh họ 8 từ bình diện liên nhân. Ngôn ngũu, 9(340), trang 28-54. 


\section{Tiếng Anh}

Adam, Q. A. (2014). Study of power relations in doctorpatient interactions in selected hospital in Lagos State, Nigeria, Advances in Language and Literary Studies, 5(2), pp. 177-184.

Adegbite, W. \& Odebunmi, A. (2006). "Discourse tact in doctor-patient interactions in English: An analysis of diagnosis in medical communication in Nigeria.". Nordic Journal of African Studies, 15(4), pp. 499-519.

Aitchison, J. (2000). Language Change: Progress or Decay? $3^{\text {rd }}$ ed. Cambridge: Cambridge University Press.

Anita, L. S. (2015). Linguistic Aspects of Family DoctorPatient Consultations. $\mathrm{PhD}$ thesis, University of Pécs, Pécs, Hungary.

Bowles, H. (2006). Conversation Analysis and Health Communication: Updating a Developing Relationship. In Gotti, M. \& Salager-Meyer, F. (eds.), Advances in Medical Discourse Analysis: Oral and Written Contexts, pp. 43-64. Bern: Peter Lang.

Brody, H. (1997). The physician-Patient Relationship. In Robert, M. (ed.), Medical Ethics, pp. 70-99, (2 ${ }^{\text {nd }}$ ed). Boston: Jones and Bartlett Publishers.

Bruce, H (2009). Doctor patient communication. Italy: Lego Print S.r.l.

Candlin, S. (2006). Constructing knowledge, Understanding and meaning between Patients and nurses. In Gotti, M. \& Salager-Meyer, F. (eds.), Advances in Medical Discourse Analysis: Oral and Written Contexts, pp. 65-86. Bern: Peter Lang.

Eggins, S \& Slade, D. (1997). Analyzing Casual Conversation. London: Continuum.

Fairclough, N (2001). Language and Power ( $2^{\text {nd }}$ ed). London: Longman.

Fairclough, N., \& Wodak, R. (1997). Critical discourse analysis. In Van Dijk, T. A. (ed.), Discourse studies. A multidisciplinary introduction, pp. 258-284. London: Sage.

Frankel, R. (1983). The laying on of hands: aspects of the organization of gaze, touch and talk in a medical encounter. In Fisher, S \& Todd, A.D. (eds.), The Social Organization of Doctor-Patient Communication. Washington D.C.: Center for Applied Linguistics.

Frankel, R. (1990). Talking in Interviews: A Dispreference for Patient-initiated Questions in Physician-Patient. In Pasathas, G (ed.), Interactional competence, pp. 231-262. Washington: University Press of America.

Halliday, M. A. K. (1978). Language as Social Semiotic:
The Interpretation of Language and Meaning. London: Edward Arnold.

Halliday, M. A. K, (1979). Modes of Meaning and Modes of Expression: Types of Grammatical Structure and Their Determination of Different Semantic Functions. In Allerton, D. J., Carney, E., \& Holdcroft, D (eds.), Functions and Contexts in Linguistic Analysis: Essays Offered to William Haas, pp. 57-79. Cambridge. Cambridge University Press.

Halliday, M. A. K (1985). Spoken and written language. Geelong, Vic: Deakin University Press.

Halliday, M. A. K (1994). An Introduction to Functional Grammar ( $2^{\text {nd }}$ ed). London: Edward Arnold.

Halliday, M. A. K, McIntosh, A \& Strevens, P (1964). The Linguistic Sciences and Language Teaching. London: Longman.

Halliday, M. A. K. \& Hasan, R. (1976). Cohesion in English. Hong Kong: Longman.

Halliday, M. A. K \& Hasan, R. (1989). Language, context, and text: Aspects of language in a socialsemiotic perspective: Language Education $\left(2^{\text {nd }} \mathrm{ed}\right)$. Oxford: Oxford University Press.

Halliday, M. A. K. \& Matthiessen, C. M. I. M. (1999). Construing Experience Through Meaning. A Language-based Approach to Cognition. London: Cassel.

Halliday, M. A. K \& Matthiessen, C. M. I. M. (2004). An Introduction to Functional Grammar ( $\left.3^{\text {rd }} \mathrm{ed}\right)$. London: Edward Arnold.

Hasan, R. (1999). Speaking with reference to Context in Ghadessy, M. (ed.), Text and Context in Functional Linguistics, pp. 219328. Amsterdam, Philadelphia: John Benjamins Publishing Company.

Hasan, R. (2009). The place of context in a Systemic Functional Model. In Halliday, M. A. K. \& Webster, J. J. (eds.), Continuum Companion to Systemic Functional Linguistics, pp. 166-189. London and New York: Continuum.

Heath, C. (1982). "Preserving the consultation: medical record cards and professional conduct". Sociology of Health and Illness, 4, 56-74.

Heath, C. (1986). Body Movement and Speech in Medical Interaction. Cambridge: Cambridge University Press.

Heath, C. (1992). The delivery and reception of diagnosis in the general practice consultation. In Drew, $\mathrm{P}$ \& Heritage, J (eds.), Talk at Work: Interaction in Institutional settings, pp. 235-267. Cambridge: Cambridge University Press.

Helman, C. G. (1990). Culture Health and Illness (2 
ed). Oxford: Butterworth-Heinemann.

Heritage, J. (1984). Garfinkel and ethnomethodology. Cambridge: Polity Press.

Heritage, J., \& Lindström, A. (1996). "Motherhood, medicine and morality: scenes from a series of medical encounter". Research on Language and Social Interaction, 31(3\&4), Lawrence Erburn Associates, Inc, pp. 397-438.

Heritage, J., \& Stivers, T. (1999). "Online Commentary in Acute Medical Visits: A Method of Shaping Patient Expectations". Social Science and Medicine, 49(11), pp. 1501-1517.

Heritage, J., \& Maynard, D. W. (2006). Communication in medical care. Interaction between primary care physicians and patients. Cambridge, UK, New York: Cambridge University Press.

Hoàng Văn Vân (2006). Introducing Discourse Analysis. Nhà xuất bản Giáo dục: Hà nội.

Hoàng Văn Vân (2012). An Experiential Grammar of the Vietnamese Clause. Hà Nội: Giáo dục.

Hori, M. (2006). Pain expression in Japanese. In Thompson, G \& Hunston, S. (eds.), System and corpus: exploring connections, pp. 206-225. London: Equinox.

Hyden, L. C \& Mishler, E. G. (1999). "Language and Medicine". Annual Review of Applied Linguistics, 19, pp. 174-192.

Jack, S \& Tanya, S. (2013). The handbook of Conversation Analysis. Blackwell Publishing Ltd: UK.

Jones, J. F (2004). Australian Politeness for Australian ESL.

Lascaratou, C. (2003). Language in Pain. Expression or Description? The Case of Greek. Athens: Parousia.

Luo, X. (2015). "Patients' Interrogative Choices in Chinese Doctor-Patient Conversations". Studies in Sociology of Science, 6 (4), pp. 65-69.

Martin J. R (1992). English Text: System and Structure. Amsterdam: John Benjamins

Matthiessen, C. (1995). Lexicogrammatical Cartography: English Systems. Tokyo International language Science Publishers.

Mishler, E. G. (1984). The Discourse of Medicine. New Jersey: Ablex Publishing Corporation.

Monagle, J \& Thomas, D. (1994). Health Care Ethics: Critical Issues. Gaithersburg: Md, Aspen Publishers.

Montgomery, M. (1996). An introduction to language and society (2nd ed.). London: Routledge.

Nguyễn Thanh Nga (2017). "Doctor-patient power relation: a systemic functional analysis of a doctor- patient consultation”. VNU Journal Foreign Studies, 33(3), pp. 24-43.

Overlach, F. (2008). Sprache des Schmerzes, Sprechen über Schmerzen: eine grammatisch-semantishe und gespräschsanalytische Untersuchung von Schmerzausdrücken im Deutschen. Berlin: De Gruyter.

Pappas. S \& Perlman, A. (2002). "Complementary and alternative medicine. The importance of doctorpatient communication". Med Clin North Am, 86(1), pp. 1-10.

Raymond, G. ( 2010 ). Grammar and social relations: Alternative forms of yes/no - type initiating actions in health visitor interactions. In Freed, A. F \& Ehrlich, S. (eds.), 'Why do you ask?': The function of questions in institutional discourse. New York, Oxford University Press, pp. 87-107

Roter, D. L \& Hall, J. A. (1992). Doctor talking with patients/Patients talking with doctors. London: Auburn House.

Sacks, H., Schegloff, E. A., and Jefferson, G. (1974). “A simplest Systematics for the Organisation of Turn Taking for Conversation”. Language, 50(4), pp. 696-735.

Steven, I. D., Thomas, S. A., Eckerman, E., Browning, C. and Dickens E. (1999). "A patient determined general practice questionnaire". Aust Fam Physician, 28(4), pp. 8-342. 


\title{
DOCTOR - PATIENT INTERACTION AT A CONSULTANCY ROOM: A CASE STUDY IN AUSTRALIA
}

\author{
Nguyen Thanh Nga
}

Vietnam Military Medical University, 160 Phung Hung, Phuc La, Ha Dong, Hanoi, Vietnam

\begin{abstract}
This paper includes a detailed analysis of a consultation between a general practitioner and his patient in a Canberra suburb. This study illustrates the shift towards model of patient-centeredness which is applaused in Australia. The purpose of this study not only reinforces the new concept of medical consultation - patient-centeredness but also confirms the necessity of change in medical discourse and reveals the reasons that lead to the movement in doctor talk. The data was collected by note taking and recording which was later transcribed. The researcher's role was that of the passive ethnographic researcher, playing no further role in the consultation. This paper concludes that the language of the doctor cannot 'standstill' when the language of society is always changing (Helman, 1990: 64). In other words, the doctor's language in this study has obviously been affected by the language used in Australian society. The movement 'towards informality' and 'solidarity politeness' in Australian language (Jones, 2004: 6) has entailed a shift in the language of Australian doctors.
\end{abstract}

Keywords: doctor-patient consultation, Conversation Analysis (CA), Systemic Functional Linguistics (SFL) 